Article

\title{
Design of Wear-Resistant UHMWPE-Based Composites Loaded with Wollastonite Microfibers Treated with Various Silane Coupling Agents
}

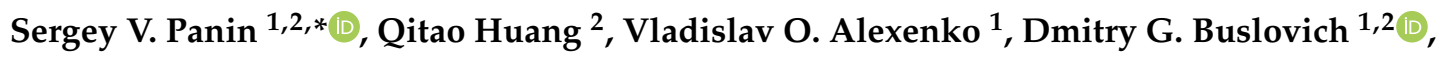 \\ Lyudmila A. Kornienko ${ }^{1}$, Filippo Berto ${ }^{3}$, Svetlana A. Bochkareva ${ }^{1}$, Iliya L. Panov ${ }^{4}$ \\ and Natalya V. Ryabova ${ }^{5}$ \\ 1 Lab. of Mechanics of Polymer Composite Materials, Institute of Strength Physics and Materials Science SB \\ RAS, 634055 Tomsk, Russia; vl.aleksenko@mail.ru (V.O.A.); buslovichdg@gmail.com (D.G.B.); \\ rosmc@ispms.ru (L.A.K.); svetlanab7@yandex.ru (S.A.B.) \\ 2 Department of Materials Science, Engineering School of Advanced Manufacturing Technologies, \\ National Research Tomsk Polytechnic University, 634030 Tomsk, Russia; qz62368396@mail.ru \\ 3 Faculty of Engineering, Department of Mechanical and Industrial Engineering, \\ Norwegian University of Science and Technology, 7491 Trondheim, Norway; filippo.berto@ntnu.no \\ 4 Department of Mechanics and Graphics, Tomsk University of Control Systems and Radioelectronic, \\ 634046 Tomsk, Russia; panov.iliya@mail.ru \\ 5 Lab. of Physical-Chemical Research Methods, Institute of Petroleum Chemistry SB RAS, 634055 Tomsk, \\ Russia; rnv@ipc.tsc.ru \\ * Correspondence: svp@ispms.ru
}

Received: 27 May 2020; Accepted: 24 June 2020; Published: 29 June 2020

\begin{abstract}
The tribomechanical properties of the wear-resistant ultrahigh molecular weight polyethylene (UHMWPE)-based composites loaded with wollastonite microfibres silanized with various coupling agents ("KH-550", “Penta-1006", and "OTS") were investigated. It was demonstrated that the mechanical properties of UHMWPE-based composites filled with various amounts of wollastonite (7-23 wt. \%) increased by 1.3 times (yield strength) and by 1.8 times (elastic modulus), while the wollastonite silanization further improved yield strength by $9 \%$ in some cases. It was demonstrated that the composite loaded with $23 \mathrm{wt}$. \% wollastonite silanized with the "KH-550" coupling agent possessed the maximum wear resistance under "moderate" conditions of tribological loading. Under "severe" conditions, the composites containing $23 \mathrm{wt}$. \% wollastonite silanized with the less efficient "OTS" and "Penta-1006" agents showed the greatest wear resistance during dry sliding friction. Wear resistance significantly depended on filler weight fraction and the load-speed mode of the tribological tests. Based on the obtained experimental data on the mechanical (including impact toughness) and tribological properties of the UHMWPE-based composites loaded with wollastonite, the optimal compositions (the filler content and the type of the coupling agent) for two load-speed modes were designed using the developed computer algorithm. The composites provided the predefined high tribomechanical properties for operation in the metal-polymer friction units compared to neat polymer.
\end{abstract}

Keywords: ultra-high molecular weight polyethylene; wollastonite; silane coupling agent; strength; adhesion; wear resistance; permolecular structure

\section{Introduction}

Currently, one of the common antifriction structural polymeric materials possessing improved strength properties and high chemical resistance in a wide range of operating temperatures (primarily 
subzero) is ultra-high molecular weight polyethylene (UHMWPE) [1-4]. Its high physical and mechanical characteristics are determined by the structure of macromolecules. During solidification from a melt, all UHMWPE elements are interconnected by transition macromolecules to one extent or another $[1,5]$. Due to its unique set of properties, UHMWPE is applied in many areas where conventional polymer grades do not withstand severe operating conditions. In addition, UHMWPE is being replaced metals in some applications and used as the only suitable material. Since the 1960s, UHMWPE has remained the most widely applied material in medicine as a component of joint endoprostheses [6-8]. In various engineering industries, UHMWPE is implemented for the manufacture of bearings, slotted and mechanical seals, as well as hydroheel discs and lightweight corrosion-resistant impellers. The use of UHMWPE as feed bearings with water lubrication in shipbuilding is expanding because of the requirement to solve the problem of the marine environment pollution with lubricating oil from sea vessels [6-11].

The main factor determining the high wear resistance of UHMWPE is its supermolecular structure. It has been found in [12-16] that reorientation of macromolecules occurs in the surface layer along the sliding direction due to the development of deformation processes caused by contact with a counterpart. This molecular reorganization process forms a structure on the friction surface oriented along the sliding direction. It also means that loading with fillers of various materials and sizes affects wear resistance, including due to changing the process nature.

It is known that neat UHMWPE wears out significantly during continuous operations, especially in dry friction conditions. Its use in extensively loaded friction units, products, and lining plates is limited by the low melting temperature, elastic modulus, and strength [17]. However, there are many ways to improve wear resistance of UHMWPE-based composites. One of the widely applied industrial methods for modifying UHMWPE is the crosslinking of macromolecules [18-20]. Nevertheless, the polymer composites can be oxidized, since not all free radicals are mobile enough to recombine with each other [21].

The UHMWPE-based nanocomposites are characterized by increased wear resistance and the low friction coefficient compared to those of neat UHMWPE [22,23]. However, the use of nanoparticles as a filler for UHMWPE is accompanied by a number of limitations, such as high costs of nanofillers, the complexity of the homogeneous nanofiller distribution in the polymer matrix, insufficient mechanical properties of the nanocomposites, their high wear rate under severe loading conditions, etc.

In addition, UHMWPE cannot be processed by methods typical for most thermoplastics due to its high molecular weight. Also, it does not interact with other materials and fillers (both organic and inorganic). In this regard, enhancing adhesion between the filler and the UHMWPE matrix is an urgent task. To date, a rather large number of studies [24-29] has been devoted to its solution.

For example, investigations of the UHMWPE-based composites containing chopped carbon fibers in amounts of up to $12 \mathrm{wt}$. \% have been carried out in [24]. As a result of annealing in air at a temperature of $500{ }^{\circ} \mathrm{C}$, an effective structure has been formed on fibers and their surface activity has been increased. Loading UHMWPE with untreated carbon fibers has increased the elastic modulus from 0.75 up to $1.54 \mathrm{GPa}$ (with their content of $10 \mathrm{wt}$. \%). In the case of preliminary thermal oxidation of fibers, the elastic modulus has reached 1.56 GPa with their content of $2 \mathrm{wt}$. \%, while it has been almost linearly increased by more than 1.5 times (up to $3.7 \mathrm{GPa}$ ) with a filling degree of $8 \mathrm{wt}$. \%.

In [29], epoxy resin composites loaded with UHMWPE fibers have been designed. They have possessed high adhesive properties due to forming interfacial membranes on the surfaces of UHMWPE fibers. The membranes have been polymerized by aldol condensation between glutaraldehyde and polyvinyl alcohol (PVA). According to energy dispersive spectral analysis and X-ray photoelectron spectroscopy, fibers treated with the "Corona-PG-2S" agent have shown an oxygen content on their surfaces of $17.3 \mathrm{wt}$. \% more compared to untreated ones. Thus, the adhesive properties have been improved due to the increase in the surface polarity. Flexural strength, ultimate cohesive force, tensile strength, and peel strength of the composites have been significantly enhanced up to $262.8 \%, 166.9 \%$, $139.7 \%$, and $200.6 \%$, respectively, compared to the samples loaded with untreated fibers. 
In [30,31], polyethylene-based composites loaded with henequen fibers modified with a silane-containing coupling agent have been studied. The results have shown that silane improved the adhesion of fibers to the matrix. Consequently, their strength increased from $71.8 \mathrm{MPa}$ for untreated fibers up to 79.3 MPa for silanized ones. However, it has been found that the resulting strength and stiffness of the composites have depended on the amount of the coupling agent deposited on fibers. The threshold value of the silane concentration has been revealed, above which tensile strength of the composites has not been improved. The efficiency of treatment with silane has been also shown in [32] by an example of epoxy composites loaded with henequen fibers. The composites loaded with silane-treated fibers have possessed a greater tensile strength than untreated ones. It has been shown that the silane concentration of $1 \mathrm{wt}$. \% has been the optimum for improving the mechanical properties.

Dayyoub et. al. [33] have grafted cellulose on the surface of a UHMWPE film by ultraviolet irradiation. Benzophenone has been applied as a coupling agent (this fact has been proved by Fourier-transform infrared spectroscopy). The best results have been obtained after one hour of preliminary treatment with mixed acids and grafted cellulose. An increase in tensile strength of $1400 \%$ has been observed, as well as a decrease in tensile strength of oriented UHMWPE films by $10 \%$. Data on contact angles have showed that treated UHMWPE films have been hydrophobic, but hydrophobicity has decreased by $17 \%$ compared to untreated ones.

In [34], the possibility of designing a coupling agent between UHMWPE and nanoparticles has been evaluated through UHMWPE powder bromination in carbon tetrachloride. Atomic force microscopy (AFM) has showed that adhesion of aluminum nitride (AIN) nanoparticles to brominated particles (Br-UHMWPE) has been higher than that of untreated polymer particles. The enhanced interaction between nanoparticles and UHMWPE has been also proved by the results of mechanical tests. Adhesion strength of AlN particles to Br-UHMWPE ones has been 3.6 times higher than that of untreated mixture. The average values were 1.26 and $4.56 \mu \mathrm{N}$, respectively. Adhesion strength increased by $45 \%$ and $260 \%$ in the cases of $\mathrm{SiC}$ and $\mathrm{AlN}$, respectively.

The design of the UHMWPE-based composites with improved mechanical and tribological properties for operating in friction units under dry sliding conditions is an industrially demanded task. The efficiency of the use of fibrous fillers, primarily to improve the mechanical properties of UHMWPE, has been shown in [35-39]. In [39], the UHMWPE-based composites loaded with wollastonite fibers (aspect ratios of 10:1, 15:1, and 20:1) have been studied. The fibers have been treated by the combined modification with a silane-titanate agent. This is a proper modifier to improve the bond between polymers and inorganic materials, because they contain both hydrophobic and hydrophilic radicals. In this case, hydrophobic radicals can bind to polymer molecules, and hydrophilic ones are able to joint with molecules of inorganic fillers. Samples have been tested using an abrasive wear tester with a rotating disc and silica sand as an abrasive. It has been shown that wear of the composites has depended on the fiber content, aspect ratio, sizes of abrasive particles, and sliding speed. Loading with wollastonite fibers at their content 5-20 wt. \% has improved abrasion resistance of the UHMWPE-based composites. The maximum abrasion resistance has been found at a content of $10 \mathrm{wt}$. \% and an aspect ratio of 20:1. For comparison, volumetric wear has been $102 \mathrm{~mm}^{3}$ for neat UHMWPE, $73 \mathrm{~mm}^{3}$ for one loaded with $10 \mathrm{wt}$. \% untreated fibers, and $62 \mathrm{~mm}^{3}$ for the polymer filled with the functionalized ones. An increase in the fiber aspect ratio has been the most important factor in improving abrasion resistance. Additionally, abrasive wear of the composites has been mainly due to plastic strains, micro-ploughing, micro-cutting, and the formation of micro-cracks.

In [40], wollastonite particles have been loaded in porous alumina and UHMWPE by electrophoretic deposition (EPD) to fabricate the alumina-wollastonite and UHMWPE-wollastonite composites. They have been impregnated with simulated body fluid (SBF) to evaluate their apatite-forming ability. Apatite has been induced from wollastonite particles deposited on the composite surfaces. The apatite-forming ability in SBF has been used as an indicator of biological activity. Adhesion strength of the apatite layer with the substrates has reached $8.9 \mathrm{MPa}$ for alumina and 5.2 MPa for UHMWPE. Thus, the designed alumina-wollastonite and UHMWPE-wollastonite composites can be used as bone substitutes. 
In recent years, fibrous wollastonite, as an inexpensive natural biocompatible mineral filler composed of calcium and silicon oxides (metasilicate $\mathrm{CaSiO}_{3}$ ), has become a common alternative to fiberglass. It is used in the form of needle-shaped particles with sizes (lengths) from 2 up to $40 \mu \mathrm{m}$ [41]. Also, it is often applied as a reinforcing filler, which improves both tensile strength and bending strength of the composites. The wollastonite acicular (fibrous) shape provides characteristics comparable to those of fiberglass [42]. As reinforcing additives, wollastonite is typically loaded in an amount up to $20 \mathrm{wt}$. \% for hardening polyethylene and polypropylene. This improves tensile strength by $\sim 30 \%$, bending strength by $\sim 20 \%$, as well as impact toughness and the elastic modulus by $\sim 60 \%$ [43].

As in the case of other silicate minerals (for example, fiberglass), the freshly milled surfaces of wollastonite particles attract hydroxyl groups (from water), ensuring adhesion to non-polar polymers [44]. However, it is believed that wollastonite treatment with silane-containing coupling agents improves both adhesion and dispersion [45-47]. It has been shown in [42] that the fiberglass silanization significantly increases wear resistance and mechanical properties of the UHMWPE composites.

In the present paper, the tasks have been solved to design of the UHMWPE-based composites with improved mechanical and tribological properties (compared to neat polymer), and to evaluate the role of increasing interfacial adhesion due to the silanization of wollastonite fibers with various silane-containing coupling agents. The composites are intended to be operated in the metal-polymer tribological units under conditions of dry sliding friction at different load-speed parameters.

\section{Materials and Methods}

The "Ticona GUR 2122" UHMWPE powder (Celanese Corporation, Irving, TX, USA; Figure 1a) was used for sample fabrication. Natural wollastonite fibers were also added as a filler (diameter of $10 \mu \mathrm{m}$, aspect ratio of 5:1; produced by GEOKOM CJSC, Kaluga region, Russia; Figure 1b).

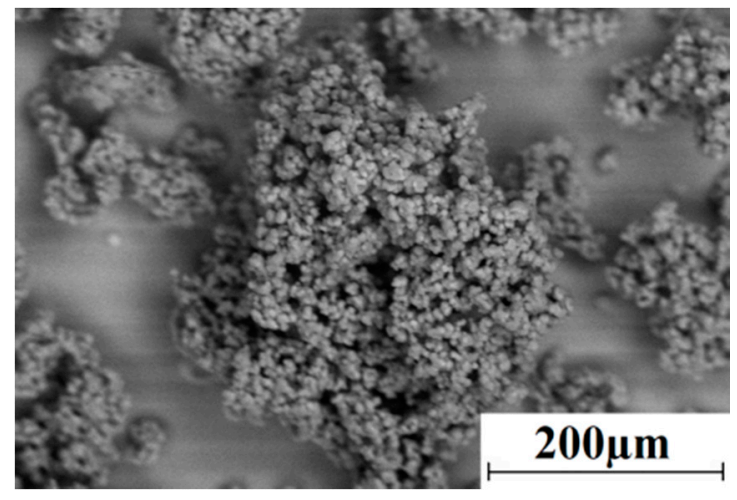

(a)

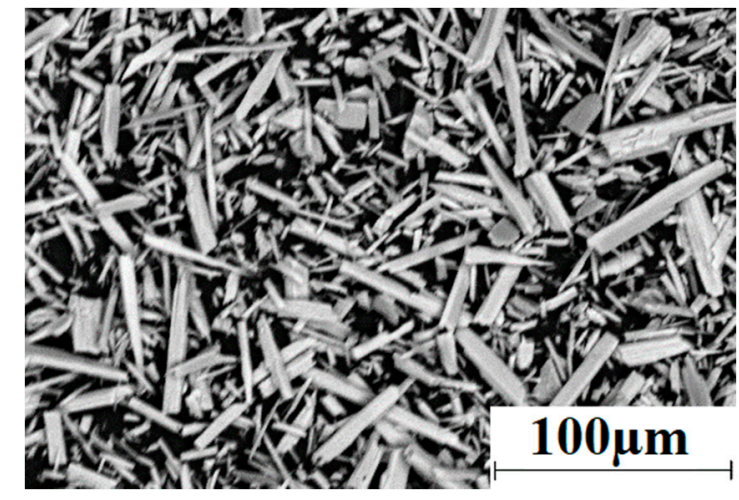

(b)

Figure 1. SEM-micrographs of the powder: (a) GUR 2122 and (b) wollastonite.

The following silane-containing coupling agents were used:

- " “KH-550" ( $\mathrm{NH}_{2} \mathrm{CH}_{2} \mathrm{CH}_{2} \mathrm{CH}_{2} \mathrm{Si}\left(\mathrm{OC}_{2} \mathrm{H}_{5}\right)_{3}$, DFRPT Co., Ltd., Guangdong, China).

- "Penta-1006" (polyorganosiloxane, $\left.\left(\mathrm{CH}_{3}\right)_{3} \mathrm{SiO}\left(\left(\mathrm{CH}_{3}\right) 2 \mathrm{SiO}\right)_{\mathrm{n}}-\mathrm{Si}\left(\mathrm{CH}_{3}\right)_{3}\right)$, PENTA-91 Company LLC, Moscow, Russia).

- "OTS" (Trimethoxy(octadecyl)silane, $\left.\mathrm{CH}_{3}\left(\mathrm{CH}_{2}\right) 17 \mathrm{Si}\left(\mathrm{OCH}_{3}\right)_{3}\right)$, Nanjing Chemical Reagent Co., Ltd., Nanjing, China).

Wollastonite fibers were treated with a water-ethanol $(\mathrm{pH}=4.5-5.5)$ solution of the "KH-550" by continuous stirring at room temperature for $30 \mathrm{~min}$. The "KH-550" weight fraction was $1 \%$ Treatment with the "Penta-1006" and "OTS" silane-containing coupling agents was according to the same procedure as the "KH-550" one. UHMWPE and wollastonite fibers were mixed and prepared much like the techniques described in [42]. 
For uniaxial static tensile testing, "dog-bone" shaped specimens, with a gauge-dimension of $3.18 \times 9.53 \times 3.2 \mathrm{~mm}^{3}$, were cut from the samples using a milling machine. The tests were carried out using an "Instron 5582" (Instron, Norwood, MA, USA) universal electro-mechanical testing machine at room temperature.

The mechanical properties were examined according to ASTM D638 (Standard Test Method For Tensile Properties Of Plastics). The tensile tests of "dog-bone" specimens (Type V) were carried out using an "INSTRON 5582" electro-mechanical testing machine. Four samples were studied with the following dimensions: thickness $(\mathrm{T})$ of $3.2 \times 0.4 \mathrm{~mm}$; narrow section width $(\mathrm{W})$ of $3.18 \times 0.5 \mathrm{~mm}$; narrow section length $(\mathrm{L})$ of $9.53 \times 0.5 \mathrm{~mm}$; width overall $(\mathrm{WO})$ of $=9.53+3.18 \mathrm{~mm}$; length overall (LO) of $63.5 \times 0.4 \mathrm{~mm}$; gauge length $(\mathrm{G})$ of $7.62 \times 0.25 \mathrm{~mm}$; distance between grips (D) of $25.4 \times 5 \mathrm{~mm}$; and fillet radius $(\mathrm{R})$ of $12.7 \times 1 \mathrm{~mm}$. The tests were conducted with the displacement control at crosshead speed of $10 \mathrm{~mm} / \mathrm{min}$. The load capacity of the testing machine was $100 \mathrm{kN}$. Strains were measured by the strain gauge of the testing machine and then corrected by the real length of each failed specimen (equal to its elongation at break).

Charpy impact strength tests were carried out using a "KM-5" pendulum hammer (ZIP LLC, Ivanovo, Russia) in accordance with ASTM D 6110 (ISO 179). The size of the specimens was $50 \times 6 \times 4 \mathrm{~mm}^{3}$. They possessed a V-shaped notch with a depth of $2 \mathrm{~mm}$ and a radius of curvature of $0.25 \mathrm{~mm}$. At least four specimens of each type were tested. The arithmetic average of the all obtained results was taken as the impact toughness value.

IR spectra were registered with the use of a "NICOLET 5700" spectrometer (Thermo Fisher Scientific, Waltham, MA, USA).

Wear resistance was evaluated using a "2070 SMT-1" friction testing machine (Tochpribor Production Association, Ivanovo, Russia) according to the "block-on-ring" scheme. Load $(P)$ was 60 and $140 \mathrm{~N}$; contact pressure was 9.7 and $32.4 \mathrm{MPa}$; and sliding speed $(V)$ was 0.3 and $0.5 \mathrm{~m} \cdot \mathrm{s}^{-1}$. Two combinations of the $P \cdot V$ conditions were applied. The "moderate" mode was at $P=60 \mathrm{~N}$ and $V=0.3 \mathrm{~m} \cdot \mathrm{s}^{-1}$, as well as the "severe" one was at $P=140 \mathrm{~N}$ and $V=0.5 \mathrm{~m} \cdot \mathrm{s}^{-1}$. A counterpart was made of the outer ring of the GCr15 bearing steel (HRC 60). It had a disk shape with a diameter of $35 \mathrm{~mm}$ and a width of $11 \mathrm{~mm}$. The counterpart surface roughness was $0.20-0.25 \mu \mathrm{m}$. Wear rate was determined by measuring width and depth of the wear track according to stylus profilometry, followed by multiplication by its length. The wear rate values were calculated, considering the data on the applied load and the sliding distance:

$$
\text { Wear rate }=\frac{\text { volume loss }\left(\mathrm{mm}^{3}\right)}{\operatorname{load}(\mathrm{N}) \cdot \text { sliding distance }(\mathrm{m})}
$$

The wear track profiles were determined using the data on at least ten tracks. Then, the wear rate values were estimated on the basis of the experimental test data over at least four samples of each type. The experimental results were processed by mathematical statistics methods.

Friction coefficients were measured using a "CSEM CH-2000" tribometer (CSEM Company, Neuchâtel, Switzerland) in accordance with ASTM G99 (the "pin-on-disk" scheme) at the following conditions: load of $5 \mathrm{~N}$; sliding speed of $0.3 \mathrm{~m} \cdot \mathrm{s}^{-1}$; sliding distance of $1000 \mathrm{~m}$, and track radius of $10 \mathrm{~mm}$. A bearing steel ball $(\emptyset 6 \mathrm{~mm}$, hardness of $60 \mathrm{HRC})$ was used as a counterpart.

Wear track surfaces and supermolecular structure were studied according to the techniques presented in [48].

\section{Experimental Results and Discussion}

\subsection{Mechanical Properties and the Permolecular Structure}

The physical and mechanical properties of neat UHMWPE and the UHMWPE-based composites, including those determined by tensile testing (Figure 2), are shown in Tables 1-4. It follows from Table 1 that loading UHMWPE with wollastonite in the studied content range caused an improvement 
in shore D hardness, elastic modulus, and yield strength by $20-70 \%$. At the same time, elongation at break, tensile strength, and impact toughness decreased as its content enhanced.

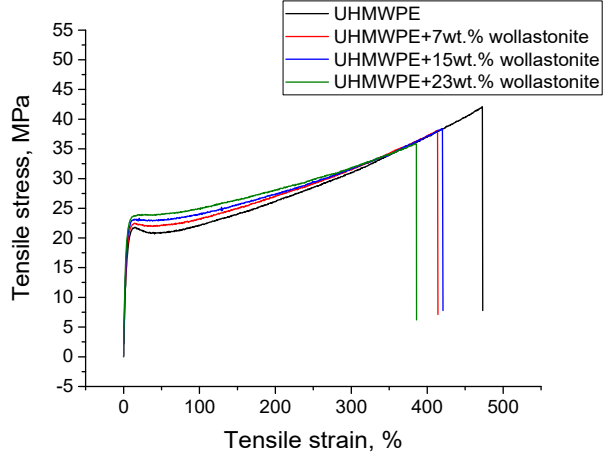

(a)

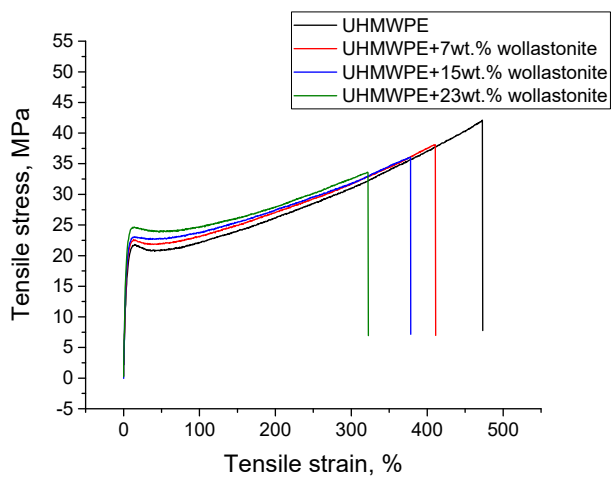

(c)

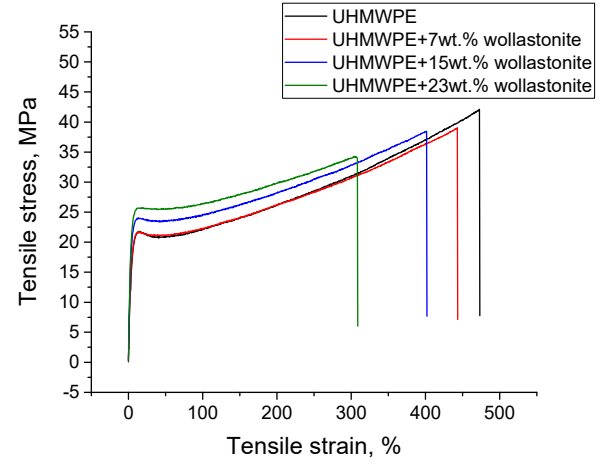

(b)

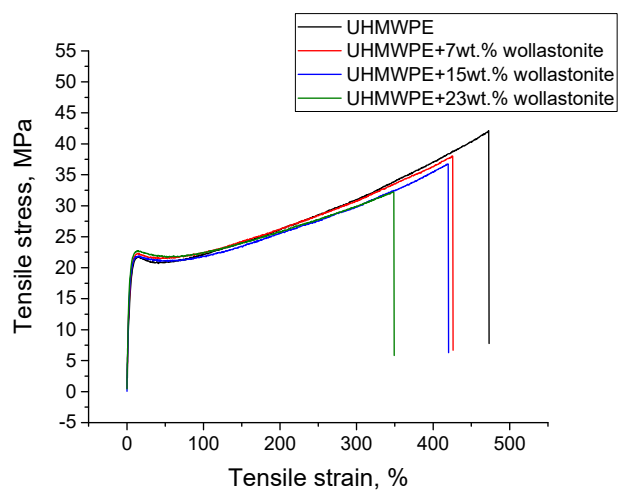

(d)

Figure 2. Engineering stress-strain curves of neat ultrahigh molecular weight polyethylene (UHMWPE) and the UHMWPE-based composites: (a) untreated; (b) "KH-550"; (c) "Penta-1006"; and (d) "OTS".

Table 1. The physico-mechanical properties of neat ultrahigh molecular weight polyethylene (UHMWPE) and the UHMWPE-based composites; untreated.

\begin{tabular}{|c|c|c|c|c|c|c|c|}
\hline $\begin{array}{c}\text { Filler } \\
\text { Composition, wt. \% }\end{array}$ & $\begin{array}{l}\text { Density } \\
(\rho), \mathrm{g} \cdot \mathrm{cm}^{-3}\end{array}$ & $\begin{array}{l}\text { Shore }(D) \\
\text { Hardness }\end{array}$ & $\begin{array}{c}\text { Elastic } \\
\text { Modulus } \\
(G), \mathrm{MPa}\end{array}$ & $\begin{array}{c}\text { Yield } \\
\text { Strength } \\
\left(\sigma_{\mathrm{Y}}\right), \mathrm{MPa}\end{array}$ & $\begin{array}{c}\text { Tensile } \\
\text { Strength } \\
\left(\sigma_{U}\right), \text { MPa }\end{array}$ & $\begin{array}{c}\text { Elongation } \\
\text { at Break } \\
(\varepsilon), \%\end{array}$ & $\begin{array}{c}\text { Impact } \\
\text { Toughness } \\
\left(\text { a) }, \mathrm{kJ} \cdot \mathrm{m}^{-2}\right.\end{array}$ \\
\hline None & 0.934 & $57.5 \pm 0.1$ & $711 \pm 40$ & $21.6 \pm 0.6$ & $42.9 \pm 3.1$ & $485 \pm 28$ & $151 \pm 6$ \\
\hline $7 \%$ wollastonite & 0.975 & $57.8 \pm 0.2$ & $858 \pm 84$ & $21.9 \pm 0.2$ & $37.8 \pm 3.0$ & $414 \pm 18$ & $123 \pm 9$ \\
\hline $15 \%$ wollastonite & 1.009 & $58.9 \pm 0.4$ & $1037 \pm 23$ & $22.4 \pm 0.1$ & $38.0 \pm 3.0$ & $424 \pm 20$ & $121 \pm 11$ \\
\hline $23 \%$ wollastonite & 1.083 & $60.4 \pm 0.2$ & $1208 \pm 54$ & $23.2 \pm 0.1$ & $35.2 \pm 3.0$ & $383 \pm 16$ & $101 \pm 10$ \\
\hline
\end{tabular}

Table 2. The physico-mechanical properties of neat ultrahigh molecular weight polyethylene UHMWPE and the UHMWPE-based composites silanized with the "KH-550" coupling agent.

\begin{tabular}{cccccccc}
\hline $\begin{array}{c}\text { Filler } \\
\text { Composition, wt. \% }\end{array}$ & $\begin{array}{c}\text { Density } \\
(\boldsymbol{\rho}) \mathbf{g} \mathbf{g} \mathbf{c m}^{-3}\end{array}$ & $\begin{array}{c}\text { Shore }(\boldsymbol{D}) \\
\text { Hardness }\end{array}$ & $\begin{array}{c}\text { Elastic } \\
\text { Modulus } \\
(\boldsymbol{G}), \mathbf{M P a}\end{array}$ & $\begin{array}{c}\text { Yield } \\
\text { Strength } \\
\left(\boldsymbol{\sigma}_{\mathbf{Y}}\right), \mathbf{M P a}\end{array}$ & $\begin{array}{c}\text { Tensile } \\
\text { Strength } \\
\left(\boldsymbol{\sigma}_{\mathbf{U}}\right), \mathbf{M P a}\end{array}$ & $\begin{array}{c}\text { Elongation } \\
\text { at Break } \\
(\boldsymbol{\varepsilon}), \mathbf{\%}\end{array}$ & $\begin{array}{c}\text { Impact } \\
\text { Toughness } \\
(\boldsymbol{a}), \mathbf{k J} \cdot \mathbf{m}^{-2}\end{array}$ \\
\hline $\begin{array}{c}\text { None } \\
7 \% \text { wollastonite + } \\
\text { "KH-550" }\end{array}$ & 0.934 & $57.5 \pm 0.1$ & $711 \pm 40$ & $21.6 \pm 0.6$ & $42.9 \pm 3.1$ & $485 \pm 28$ & $151 \pm 6$ \\
$\begin{array}{c}15 \% \text { wollastonite + } \\
\text { "KH-550" }\end{array}$ & 0.976 & $57.8 \pm 0.3$ & $885 \pm 60$ & $22.2 \pm 0.6$ & $39.9 \pm 0.7$ & $441 \pm 15$ & $125 \pm 9$ \\
$\begin{array}{c}23 \% \text { wollastonite + } \\
\text { "KH-550" }\end{array}$ & 1.029 & $59.1 \pm 0.4$ & $1009 \pm 88$ & $23.8 \pm 0.5$ & $38.4 \pm 1.6$ & $404 \pm 27$ & $123 \pm 11$ \\
\hline
\end{tabular}


Table 3. The physico-mechanical properties of neat ultrahigh molecular weight polyethylene UHMWPE and the UHMWPE-based composites silanized with the "Penta-1006" coupling agent.

\begin{tabular}{cccccccc}
\hline $\begin{array}{c}\text { Filler } \\
\text { Composition, wt. \% }\end{array}$ & $\begin{array}{c}\text { Density } \\
(\boldsymbol{\rho}) \mathbf{g} \cdot \mathbf{g} \mathbf{c m}^{-3}\end{array}$ & $\begin{array}{c}\text { Shore }(\boldsymbol{D}) \\
\text { Hardness }\end{array}$ & $\begin{array}{c}\text { Elastic } \\
\text { Modulus } \\
(\boldsymbol{G}), \mathbf{M P a}\end{array}$ & $\begin{array}{c}\text { Yield } \\
\text { Strength } \\
\left(\boldsymbol{\sigma}_{\mathbf{Y}}\right), \mathbf{M P a}\end{array}$ & $\begin{array}{c}\text { Tensile } \\
\text { Strength } \\
\left(\sigma_{\mathbf{U}}\right), \mathbf{M P a}\end{array}$ & $\begin{array}{c}\text { Elongation } \\
\text { at Break } \\
(\varepsilon), \%\end{array}$ & $\begin{array}{c}\text { Impact } \\
\text { Toughness } \\
(\boldsymbol{a}), \mathbf{k J} \cdot \mathbf{m}^{-2}\end{array}$ \\
\hline $\begin{array}{c}\text { None } \\
7 \% \text { wollastonite }+ \\
\text { "Penta-1006" }\end{array}$ & 0.934 & $57.5 \pm 0.1$ & $711 \pm 40$ & $21.6 \pm 0.6$ & $42.9 \pm 3.1$ & $485 \pm 28$ & $151 \pm 6$ \\
$\begin{array}{c}15 \% \text { wollastonite + } \\
\text { "Penta-1006" }\end{array}$ & 1.035 & $59 \pm 0.4$ & $977 \pm 59$ & $22.9 \pm 0.4$ & $35.9 \pm 2.2$ & $378 \pm 36$ & $114 \pm 10$ \\
$\begin{array}{c}\text { 23\% wollastonite + } \\
\text { "Penta-1006" }\end{array}$ & 1.100 & $60.3 \pm 0.5$ & $1102 \pm 96$ & $24.4 \pm 0.3$ & $33.4 \pm 6.3$ & $322 \pm 32$ & $89 \pm 7$ \\
\hline
\end{tabular}

Table 4. The physico-mechanical properties of the neat UHMWPE and the UHMWPE-based composites silanized with the "OTS" coupling agent.

\begin{tabular}{|c|c|c|c|c|c|c|c|}
\hline $\begin{array}{c}\text { Filler } \\
\text { Composition, wt. \% }\end{array}$ & $\begin{array}{l}\text { Density } \\
(\rho), \mathrm{g} \cdot \mathrm{cm}^{-3}\end{array}$ & $\begin{array}{l}\text { Shore }(D) \\
\text { Hardness }\end{array}$ & $\begin{array}{c}\text { Elastic } \\
\text { Modulus } \\
(G), \mathrm{MPa}\end{array}$ & $\begin{array}{c}\text { Yield } \\
\text { Strength } \\
\left(\sigma_{\mathrm{Y}}\right), \mathrm{MPa}\end{array}$ & $\begin{array}{c}\text { Tensile } \\
\text { Strength } \\
\left(\sigma_{U}\right), \mathrm{MPa}\end{array}$ & $\begin{array}{c}\text { Elongation } \\
\text { at Break } \\
(\varepsilon), \%\end{array}$ & $\begin{array}{c}\text { Impact } \\
\text { Toughness } \\
(a), \mathrm{kJ} \cdot \mathrm{m}^{-2}\end{array}$ \\
\hline None & 0.934 & $57.5 \pm 0.1$ & $711 \pm 40$ & $21.6 \pm 0.6$ & $42.9 \pm 3.1$ & $485 \pm 28$ & $151 \pm 6$ \\
\hline $\begin{array}{c}\text { 7\% wollastonite + } \\
\text { "OTS" }\end{array}$ & 0.979 & $57.2 \pm 0.2$ & $849 \pm 41$ & $22.1 \pm 0.3$ & $38.0 \pm 3.1$ & $422 \pm 16$ & $120 \pm 4$ \\
\hline $\begin{array}{c}\text { 15\% wollastonite + } \\
\text { "OTS" }\end{array}$ & 1.034 & $59.9 \pm 0.2$ & $946 \pm 85$ & $22.4 \pm 0.5$ & $37.5 \pm 1.0$ & $420 \pm 25$ & $119 \pm 7$ \\
\hline $\begin{array}{l}23 \% \text { wollastonite + } \\
\text { "OTS" }\end{array}$ & 1.102 & $60.2 \pm 0.3$ & $1078 \pm 109$ & $22.5 \pm 0.4$ & $31.5 \pm 1.0$ & $349 \pm 14$ & $89 \pm 8$ \\
\hline
\end{tabular}

The wollastonite functionalization with the "KH-550" coupling agent did not result in a notable increase in the mechanical properties of the composites relative to those with untreated fibers. However, yield strength was improved by $9 \%$ (Table 2). In addition, elongation at break and impact toughness significantly decreased, but only for the composite with a high wollastonite content ( $23 \mathrm{wt}$. \%).

Tensile and yield strength as well as elastic modulus of the composites functionalized with the "Penta-1006" coupling agent were lower than those of the ones silanized with "KH-550" (Table 3) and were close to the values of these characteristics treated with "OTS" (Table 4).

Thus, an analysis of the physical and mechanical properties of the UHMWPE-based composites loaded with wollastonite fibers (both untreated and silanized with the coupling agents) enabled to conclude that the high values were mainly due to the "mechanical" adhesion of the non-polar UHMWPE matrix to the filler, determined by its complex (needle) shape [42]. Additional chemical adhesion due to the functionalization of fibers with the studied coupling agents ("KH-550", "Penta-1006", and "OTS") to a lesser extent affected the possibility of improving the mechanical properties of the composites at all filler contents. The permolecular structure of the investigated composites testified in favor of the foregoing (Figure 3). 


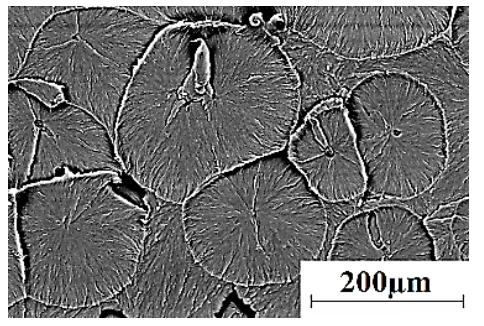

(a)

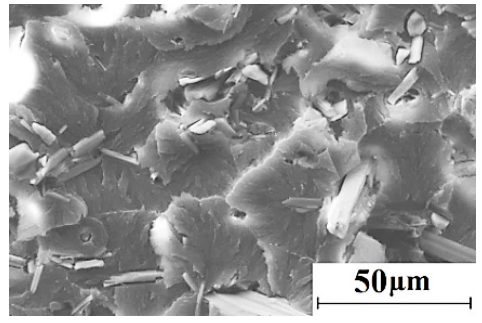

(d)

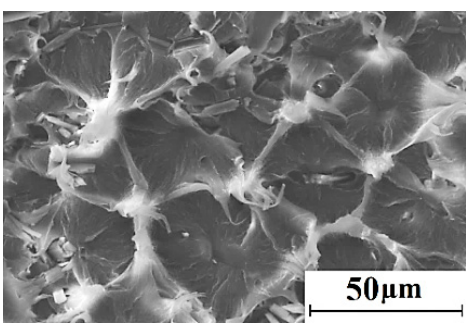

(b)

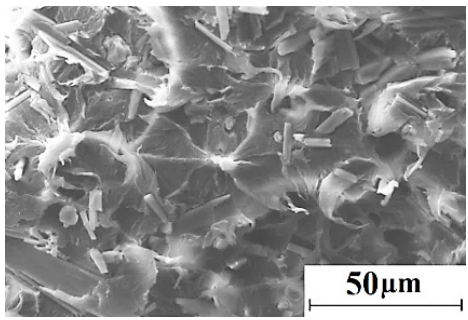

(e)

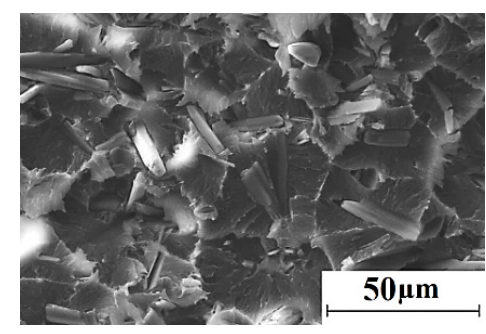

(c)

Figure 3. SEM micrographs of the permolecular structure of neat UHMWPE (a) and the composites: UHMWPE + 15 wt. \% wollastonite (b), UHMWPE + 15 wt. \% wollastonite + “KH-550" (c), UHMWPE + 15 wt. \% wollastonite + "Penta-1006" (d), and UHMWPE + 15 wt. \% wollastonite + "OTS" (e).

It can be concluded from the SEM micrographs presented in Figure 3 that the similarity of the permolecular structure (small spherulites with evenly distributed microfibers) was in the composites with wollastonite both untreated and functionalized with all three studied coupling agents. Moreover, the spherulitic nature of the permolecular structure was observed at high loading degrees as well (up to 23 wt. \%, Figure 4 ).

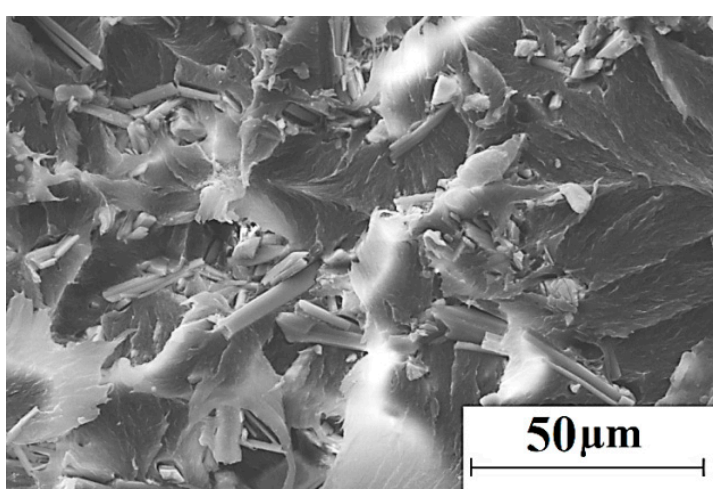

(a)

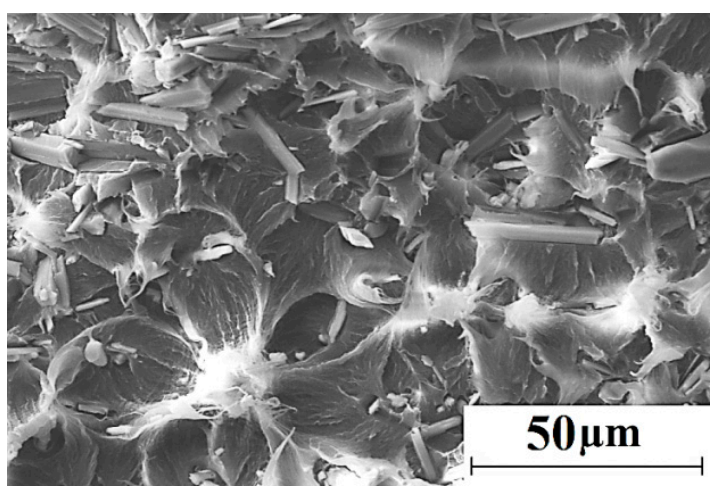

(b)

Figure 4. SEM micrographs of permolecular structure of the composites: UHMWPE $+23 \mathrm{wt}$. \% wollastonite (a) and UHMWPE + 23 wt. \% wollastonite + "KH-550" (b).

An analysis of the FT-IR spectra of the composites loaded with wollastonite (both untreated and silanized) showed that the functionalization with the studied coupling agents contributed to the appearance of additional relatively weak peaks reflecting the formation of a chemical bond between the coupling agents and wollastonite (inverse wavelength range of $1100-759 \mathrm{~cm}^{-1}$, Figure 5). The pronounced absorption peak at $717 \mathrm{~cm}^{-1}$ was a characteristic one of $\mathrm{SiCH}_{2}$. The peak at $800 \mathrm{~cm}^{-1}$ was characteristic of $\mathrm{Si}\left(\mathrm{CH}_{3}\right)_{2}$, while at 1028 and $1090 \mathrm{~cm}^{-1}$ there were twin absorption peaks of Si-O $[42,45]$. 


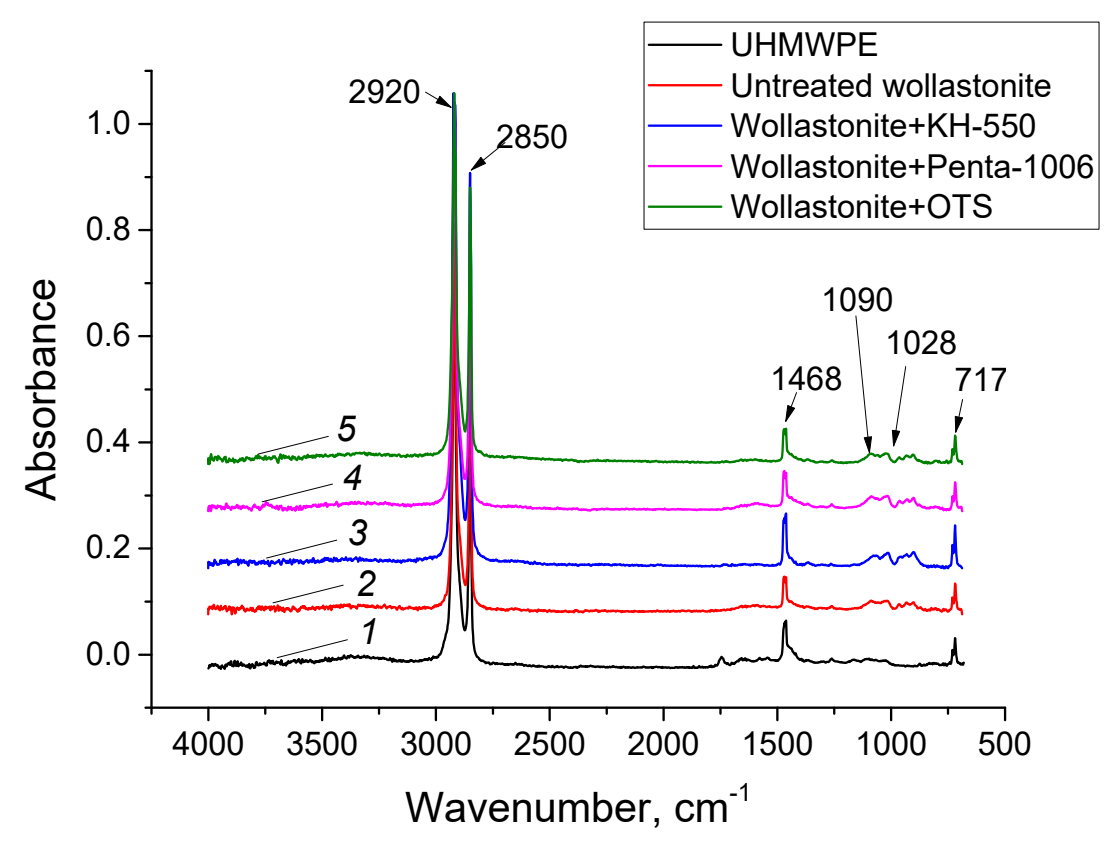

Figure 5. FT-IR spectra of neat UHMWPE and the UHMWPE-based composites.

It follows from the analysis of the IR-spectra that the intensities of the characteristic peaks of $\mathrm{SiCH}_{2}$ $\left(717 \mathrm{~cm}^{-1}\right)$ were slightly enhanced in the composites with functionalized wollastonite in comparison to those with the untreated one. The degree of increase in $\mathrm{SiCH}_{2}$ peaks was governed by chemical bonding with the modifier. The peaks at 1090 and $1028 \mathrm{~cm}^{-1}$ were due to the presence of Si-O bonds and remained almost unchanged after the wollastonite functionalization with the coupling agents. Thus, the improvement of the mechanical properties of the UHMWPE-based composites with untreated and silanized wollastonite (as opposed to the fiberglass functionalization with the same coupling agents) was mainly due to the "mechanical" adhesion of the complex shape filler with the polymer matrix [42]. By the term "mechanical adhesion" the authors had in mind the effective mechanical adhesion of complex-shaped fibers due to their developed surfaces, reinforced by the action of compressive stresses formed during hot pressing of the polymer tightly fitted with the filler.

\subsection{Tribological Properties}

The results of determining the friction coefficients of the UHMWPE-based composites with different contents of untreated and silanized wollastonite are shown in Table 5 and Figure 6 . It is seen that loading UHMWPE with untreated wollastonite reduced the friction coefficient for the studied filler contents (Figure 6a). In contrast, the wollastonite treatment with all three coupling agents increased the friction coefficients (Figure $6 \mathrm{~b}-\mathrm{d}$ ). Moreover, this resulted in oscillations and multidirectional change of the friction coefficient values as load and sliding speed increased. According to the authors, this could be due to the presence of the coupling agents or debris on the sliding surfaces that suppressed the bearing steel counterpart sliding.

Table 5. The friction coefficients of the UHMWPE-based composites with various wollastonite contents; the "ball-on-disk" scheme.

\begin{tabular}{cccc}
\hline Filler Content & 7 wt. \% & 15 wt. \% & 23 wt. \% \\
Coupling Agent & & & \\
\hline None & $0.085 \pm 0.019$ & $0.096 \pm 0.018$ & $0.097 \pm 0.008$ \\
"KH-550" & $0.106 \pm 0.026$ & $0.106 \pm 0.006$ & $0.114 \pm 0.018$ \\
"Penta-1006" & $0.101 \pm 0.009$ & $0.101 \pm 0.014$ & $0.115 \pm 0.014$ \\
"OTS" & $0.093 \pm 0.014$ & $0.105 \pm 0.010$ & $0.128 \pm 0.014$ \\
\hline
\end{tabular}




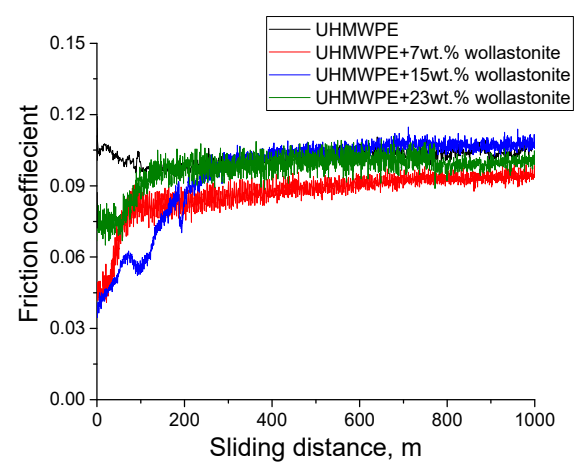

(a)

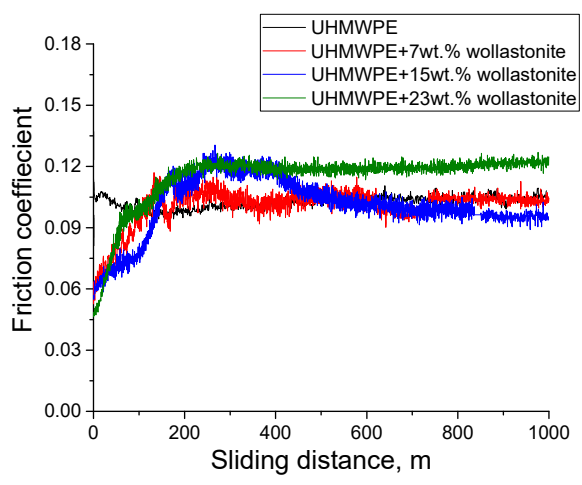

(c)

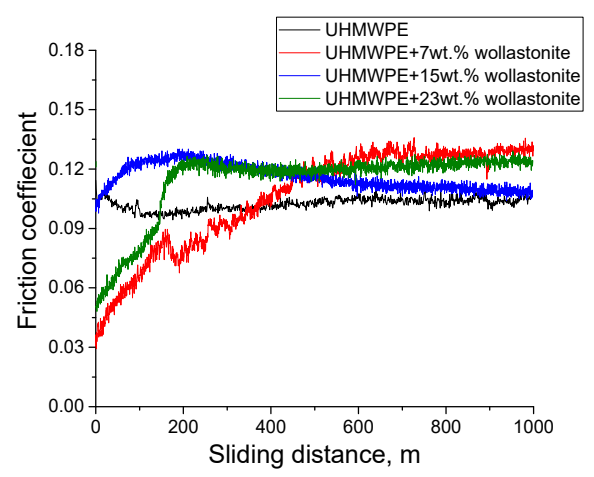

(b)

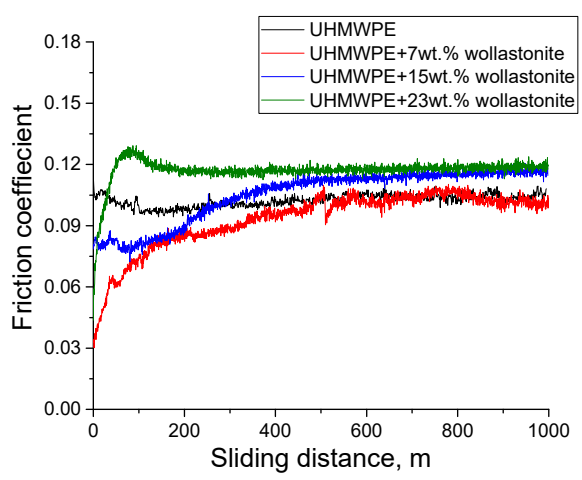

(d)

Figure 6. Diagrams on the friction coefficients vs. sliding distance: (a) without a silane-coupling agent and with (b) "KH-550", (c) "Penta-1006", and (d) "OTS": the "pin-on-disk" scheme.

In order to study the effect of the coupling agents on wear resistance of the UHMWPE-based composites under different load-speed conditions in more detail, the dry sliding friction triblogical tests were carried out according to the "pin-on-disk" scheme using the "moderate" ( $\left.\mathrm{P}=60 \mathrm{~N}, \mathrm{~V}=0.3 \mathrm{~m} \cdot \mathrm{s}^{-1}\right)$ and "severe" ( $\left.\mathrm{P}=140 \mathrm{~N}, \mathrm{~V}=0.5 \mathrm{~m} \cdot \mathrm{s}^{-1}\right)$ modes. Figure 7 shows the dependences of the change in wear rate for all studied composites as a function of the filler content. Wear resistance of the composites was determined by (i) the wollastonite content, (ii) the presence and the type of coupling agents, and (iii) the conditions of tribological loading.

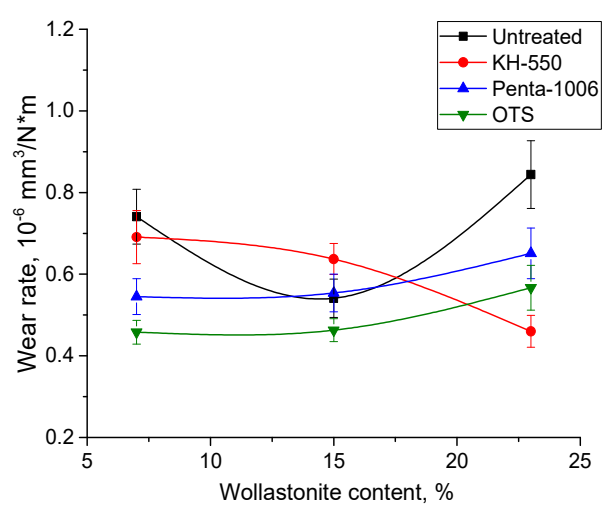

(a)

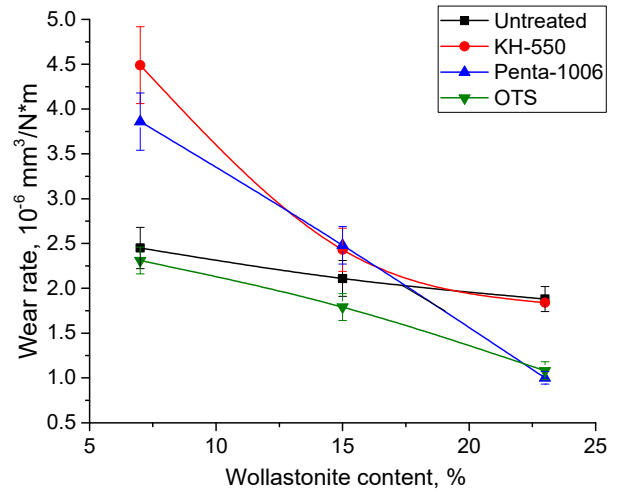

(b)

Figure 7. Diagrams on wear rate vs. filler weight fraction for the UHMWPE-based composites for (a) Load $=60 \mathrm{~N}$, Velocity $=0.3 \mathrm{~m} \cdot \mathrm{s}^{-1}$ and (b) Load $=140 \mathrm{~N}$, Velocity $=0.5 \mathrm{~m} \cdot \mathrm{s}^{-1}$ : the "block-on-ring" scheme. 
Under the "moderate" conditions of tribological loading, three characteristic trends of the curves were distinguished. In the case of untreated wollastonite, the optimum wear resistance was at a filler content of $15 \mathrm{wt}$. \% (Figure 7a, curve 1). Wear rate gradually decreased (curve 2) for the "KH-550" coupling agent which provided the maximum increase in yield strength (and, obviously, adhesion) with enhancing filler quantity. An inverse trend emerged for the other two coupling agents. Wear rate gradually rose as the silanized wollastonite content increased (curves 3 and 4).

Another pattern of the dependence of wear factor from the wollastonite content was under the "severe" conditions of tribological loading (Figure $7 \mathrm{~b}$ ). Wear rate of the composites with untreated wollastonite increased by an order of magnitude for all filler contents compared to the "moderate" conditions (curve 1). At the same time, the functionalization with the "KH-550" and "Penta-1006" coupling agents increased wear rate by 1.8 and 1.2 times at the wollastonite contents of 7 and $15 \mathrm{wt} . \%$, respectively (curves 2 and 3). The silanization with the "OTS" coupling agent linearly decreased wear rate for all filler contents (Figure $7 \mathrm{~b}$; curve 4).

Thus, the lowest wear rate was characteristic of the maximum filling degree of $23 \mathrm{wt}$. \% under the "severe" conditions. However, wear rate was more than twice as high for the untreated filler and the "KH500" coupling agent, compared to that for the silanized with the both the "Penta-1006" and "OTS" ones.

Table 6 shows the data on the counterpart temperature upon testing under the "severe" conditions of tribological loading, since its noticeable change was detected only in this case (relative to the "moderate" mode).

Table 6. Temperature $\left({ }^{\circ} \mathrm{C}\right)$ of the UHMWPE-based composites loaded with wollastonite under the "severe" conditions of tribological loading: the "pin-on-disk" scheme.

\begin{tabular}{ccccc}
\hline Filler Content & \multirow{2}{*}{$\mathbf{7 \%}$} & $\mathbf{1 5 \%}$ & $\mathbf{2 3 \%}$ & \\
Coupling Agent & & & & \\
\hline None & & $60.5 \pm 2.0$ & $60.5 \pm 2.0$ & $57.3 \pm 2.0$ \\
"KH-550" & $67.7 \pm 2.0$ & $60.5 \pm 2.0$ & $55.0 \pm 2.0$ \\
"Penta-1006" & $66.8 \pm 2.0$ & $61.0 \pm 2.0$ & $43.0 \pm 2.0$ \\
"OTS" & & $58.0 \pm 2.0$ & $53.2 \pm 2.0$ & $47.6 \pm 2.0$ \\
\hline
\end{tabular}

The functionalization contributed to a reduction in temperature. Moreover, if the yield strength value of the composite (with the filling degree of $23 \mathrm{wt}$. \%) under tension was a conditional measure of adhesion, then the silanization with different coupling agents had a different effect on the temperature variation at various wollastonite contents compared to the absence of "chemically-induced" adhesion (without functionalization). The counterpart temperature typically increased at the low filling degrees (except for the "OTS" coupling agent), almost did not change at average filling levels (again, except for the "OTS"), and always decreased at the maximum filler content. In the last case, wear rate was close enough for the composites loaded with the filler both untreated and functionalized with the "KH-500" coupling agent, as well as the counterpart temperature. The same pattern was characteristic of the relationship between wear rate and temperature for the other two types of the coupling agents. This testified in favor of a correlation between these two parameters.

The above dependences of wear rate on the filler content, the type of the coupling agent, and the tribological loading conditions were in full agreement with the observed patterns of the wear track surface topographies of the UHMWPE-based composites. Their analysis is presented below.

\subsubsection{The "Moderate" Conditions of Tribological Loading $\left(\operatorname{Load}=60 \mathrm{~N}\right.$, Velocity $\left.=0.3 \mathrm{~m} \cdot \mathrm{s}^{-1}\right)$}

Figures 8, 9 and 10show optical images of the wear track surfaces of the UHMWPE-based composites with wollastonite (both untreated and functionalized with various coupling agents) after the tribological tests under the "moderate" conditions. The wear track surfaces of all composites with the low wollastonite content $(7 \mathrm{wt}$. \%) were quite smooth (Figure 8 ). The neat UHMWPE surface 
reflected traces of the fatigue wear mechanism [48], while loading with the filler (7 wt. \%) had caused the formation of a smoother surface, regardless of the silanization and the type of the coupling agent.

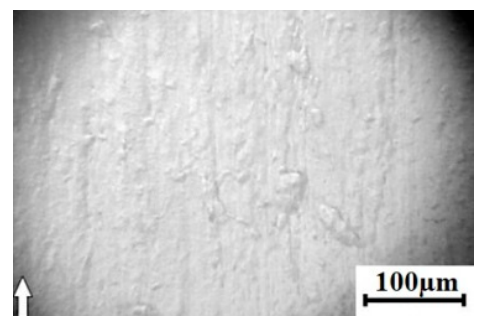

(a)

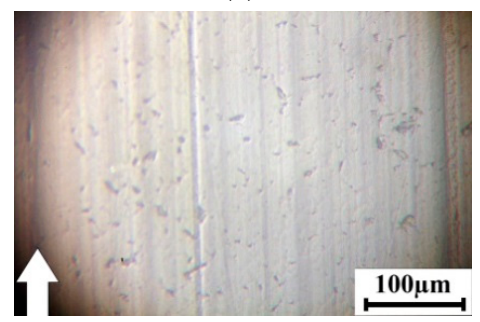

(d)

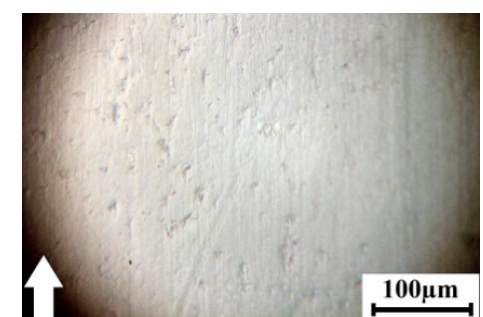

(b)

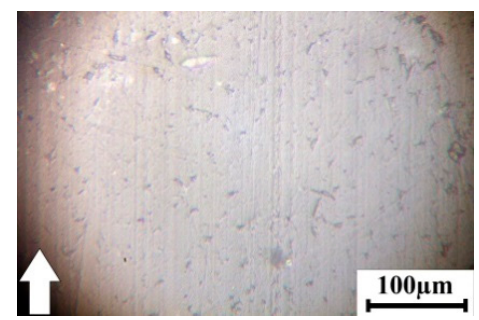

(e)

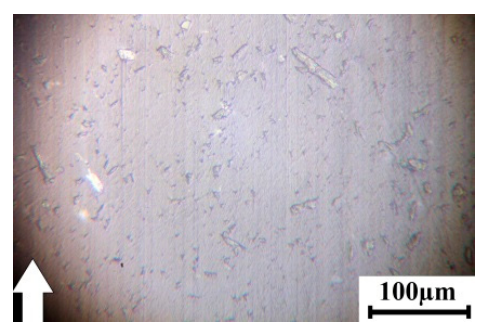

(c)

Figure 8. Optical images of the wear track surfaces of neat UHMWPE (a); and the "UHMWPE + 7 wt. \% wollastonite" composites: untreated (b); “KH-550" (c); “Penta-1006" (d); and “OTS" (e) (Load = 60 N, Velocity $\left.=0.3 \mathrm{~m} \cdot \mathrm{s}^{-1}\right)$.

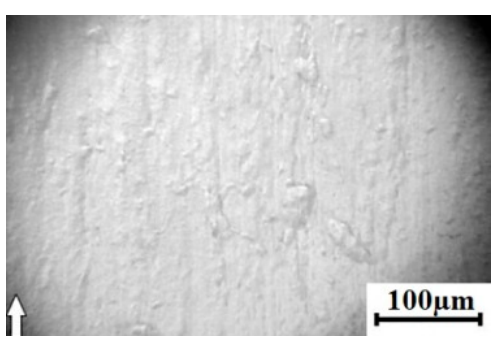

(a)

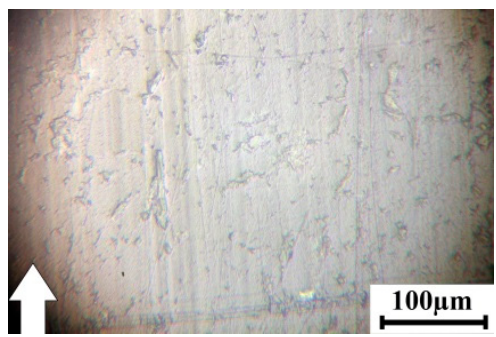

(d)

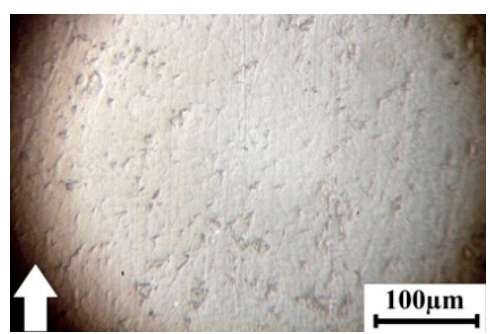

(b)

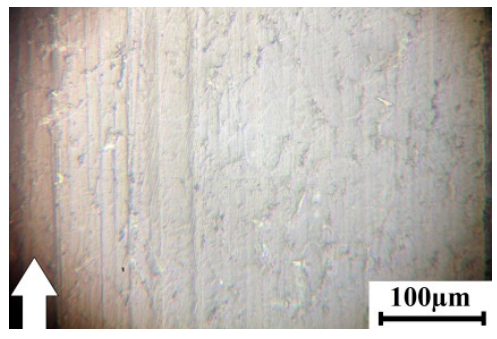

$(\mathbf{e})$

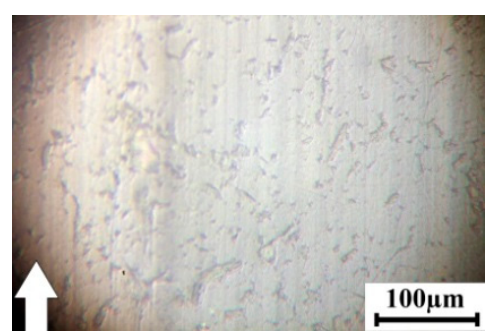

(c)

Figure 9. Optical images of the wear track surfaces of neat UHMWPE (a); and the "UHMWPE + 15 wt. \% wollastonite" composites: untreated (b); “KH-550" (c); “Penta-1006" (d); and "OTS" (e) (Load = 60 N, Velocity $\left.=0.3 \mathrm{~m} \cdot \mathrm{s}^{-1}\right)$.

Pits had appeared on the wear track surfaces of the composites with the increase in the wollastonite content up to $15 \mathrm{wt}$ \%, as well as for untreated and silanized fibers to a similar degree (Figure 9). The reason for their occurrence had been the filler detachment from the polymer matrix. In this case, both the silanization and the type of coupling agent had not significantly affected the intensity of this process. At the same time, this had not been accompanied by the micro-abrasive damage on the wear track surfaces that did not contain longitudinal micro-grooves oriented along the counterpart sliding direction. Highly likely, this was due to the low wollastonite hardness (discussed in [45] earlier). 


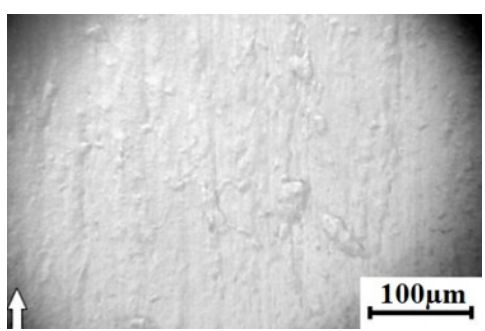

(a)

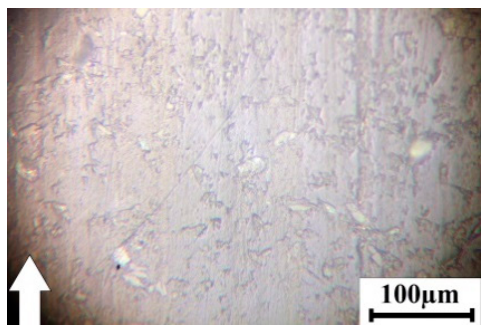

(d)

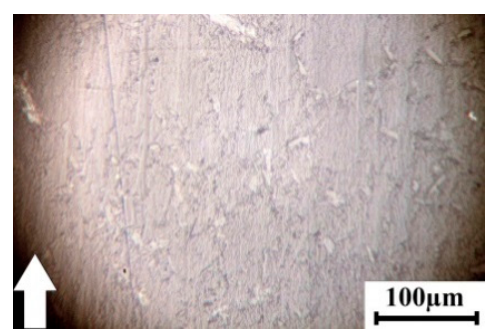

(b)

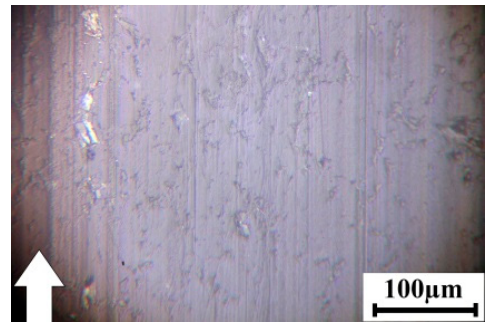

(e)

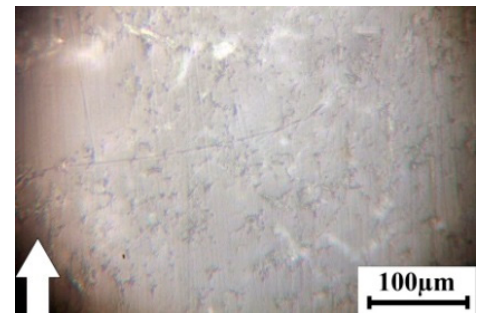

(c)

Figure 10. Optical images of the wear track surfaces of neat UHMWPE (a); and the "UHMWPE + 23 wt. \% wollastonite" composites: untreated (b); “KH-550" (c); “Penta-1006" (d); and “OTS” (e) (Load = 60 N, Velocity $\left.=0.3 \mathrm{~m} \cdot \mathrm{s}^{-1}\right)$.

The wear track surfaces of the composites containing $23 \mathrm{wt}$ \% wollastonite had a complex topology (Figure 10). On the one hand, a significant amount of the filler had to cause its detachment. As a result, the surface had to contain a lot of "pits". On the other hand, wollastonite microparticles falling on the wear track surfaces could exert a "polishing" effect. Accordingly, they had to be smoother. This was characteristic of the composite treated with the "KH-550" coupling agent (Figure 10c). A similar "polishing" effect to varying degrees was observed for the other two types of coupling agents ("Penta-1006" and "OTS"; Figure 10d,e, respectively).

It can be stated in general that the wollastonite functionalization with the studied coupling agents varied wear resistance of the UHMWPE-based composites not only due to a change in the adhesion level under the "moderate" conditions of tribological loading. As alternative mechanisms of its effect, there could be accelerating oxidation processes or exposure of the detaching filler particles on the composite wear track surfaces.

\subsubsection{The "Severe" Conditions of Tribological Loading $\left(\operatorname{Load}=140 \mathrm{~N}\right.$, Velocity $\left.=0.5 \mathrm{~m} \cdot \mathrm{s}^{-1}\right)$}

Figures 11-13 show optical images of the wear track surfaces of the UHMWPE-based composites with wollastonite (both untreated and functionalized with various coupling agents) after the tribological tests under the "severe" conditions. The increase in load and temperature of neat UHMWPE had caused the formation of creases due to the material plastic flow in the polymer surface layer along the sliding direction of the heated steel counterpart (Figure 11a). 


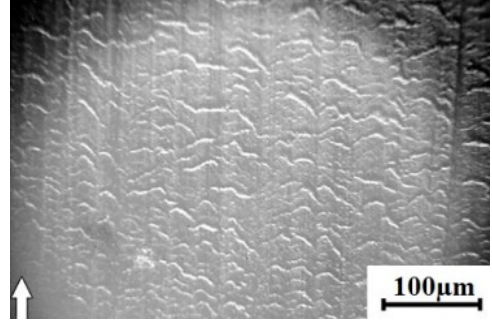

(a)

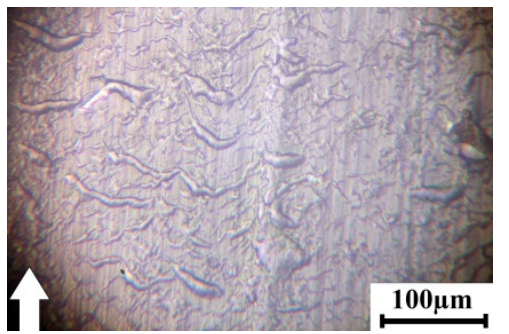

(d)

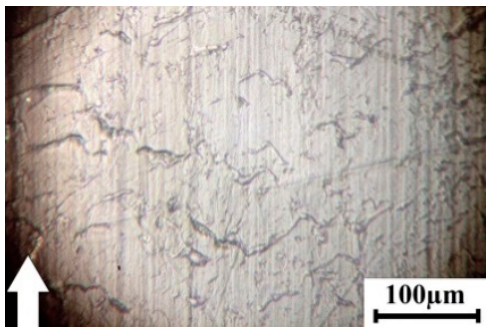

(b)

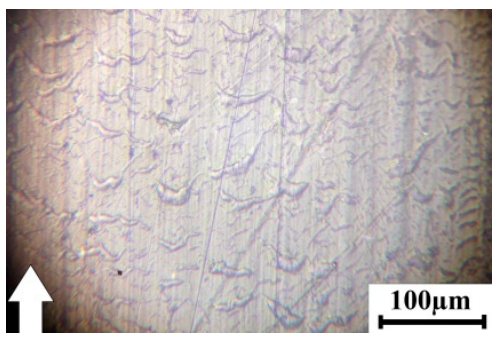

(e)

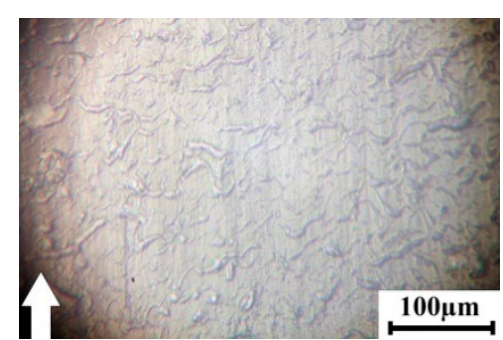

(c)

Figure 11. Optical images of the wear track surfaces of neat UHMWPE (a); and the "UHMWPE + 7 wt. \% wollastonite" composites: untreated (b); "KH-550" (c); "Penta-1006" (d); and “OTS" (e) (Load = 140 N, Velocity $\left.=0.5 \mathrm{~m} \cdot \mathrm{s}^{-1}\right)$.

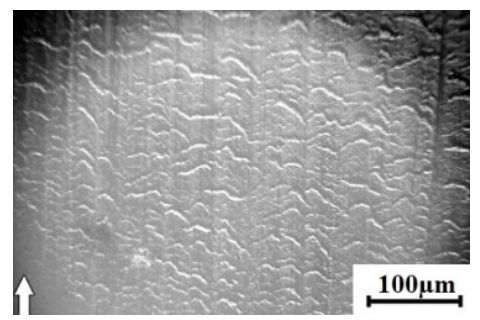

(a)

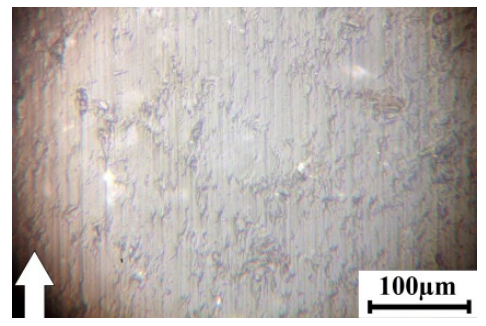

(d)

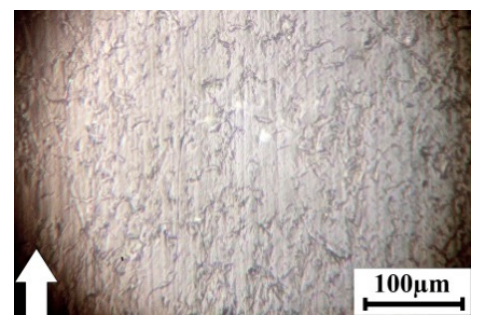

(b)

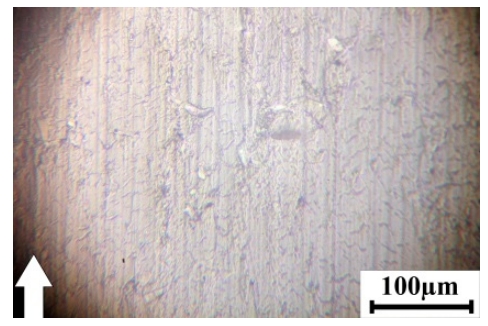

(e)

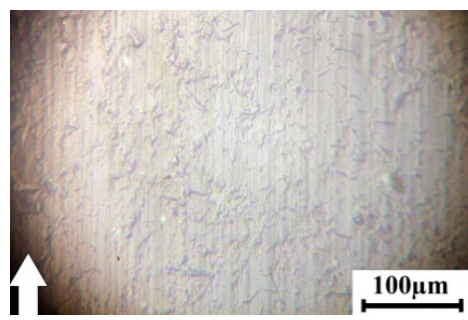

(c)

Figure 12. Optical images of the wear track surfaces of neat UHMWPE (a); and the "UHMWPE + 15 wt. \% wollastonite" composites: untreated (b); “KH-550" (c); “Penta-1006" (d); and “OTS” (e) (Load = 140 N, Velocity $\left.=0.5 \mathrm{~m} \cdot \mathrm{s}^{-1}\right)$.

The wear track surfaces of the composites with the low wollastonite content in general were similar to those for neat polymer (Figure 11). This was consistent with the counterpart temperature (Table 6). Nevertheless, the numbers of creases were slightly lower for all composites compared to neat UHMWPE (Figure 11b-e).

Increasing the filler content up to $15 \mathrm{wt}$ \% had excluded the formation of creases for all filled composites (Figure 12). The counterpart temperature was approximately the same for all four types of the composites (Table 6). It should be noted that the wear track surface of the composite with the untreated filler were quite "pitted" (Figure 12b). At the same time, the surfaces of all composites loaded with silanized wollastonite were sufficiently smooth (Figure 12c-e). Perhaps this was due to better wollatonite retention in the polymer matrix. 


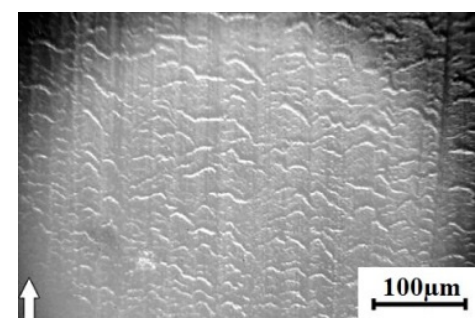

(a)

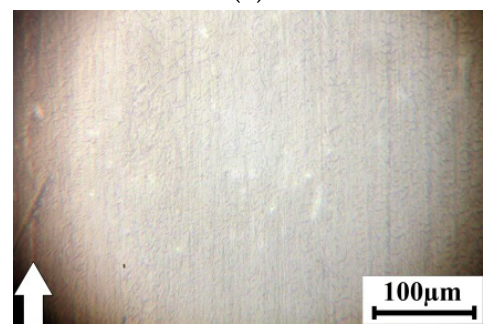

(d)

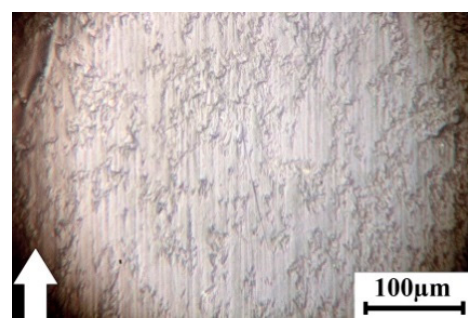

(b)

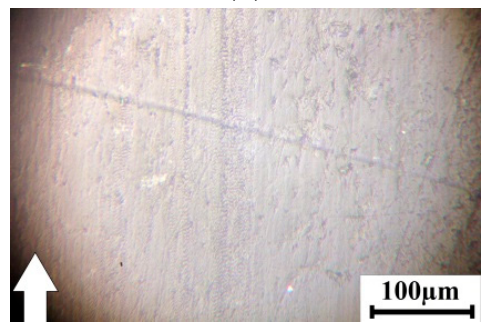

(e)

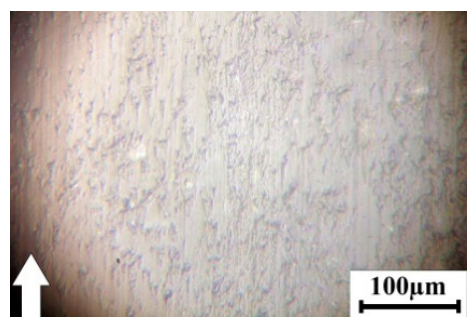

(c)

Figure 13. Optical images of the wear track surfaces of neat UHMWPE (a); and the "UHMWPE + 23 wt. \% wollastonite" composites: without silane coupling agent (b); “KH-550" (c); "Penta-1006" (d); and "OTS" (e) $\left(\right.$ Load $=140 \mathrm{~N}$, Velocity $\left.=0.5 \mathrm{~m} \cdot \mathrm{s}^{-1}\right)$.

In the case of the maximum wollastonite content (23 wt. \%; Figure 13), the wear track surfaces were similar for the composites loaded with the filler both untreated and silanized with the "KH-550" coupling agent (Figure 13b,c respectively). They possessed traces of "pits", but had similar wear resistance. Similar patterns were evident for the other two coupling agents ("Penta-1006" and "OTS"). The wear track surfaces were very smooth (probably "polished"), and wear rate was minimal as the counterpart temperature (Table 6) upon its sliding was on such a smooth surface.

Thus, an enlarging in the wollastonite weight fraction was accompanied by improving wear resistance under the "severe" conditions of tribological loading. According to the authors, an increase in both load and sliding speed resulted in an enhanced temperature in the tribological contact. This fact and the polishing effect on the wear track surfaces leveled adhesion induced by the coupling agents. Changes in the untreated wollastonite content exerted a minimum effect on wear resistance of the composites. The smallest wear was found for the composites loaded with $23 \mathrm{wt}$. \% wollastonite treated with the less effective coupling agents ("Penta-1006" and "OTS").

Since the goal of the studies was to design the composites for the metal-polymer tribological units, it was necessary to ensure load-bearing capacity, resistance to cracking and wearing at the same time. Therefore, further studies were carried out using the multi-parameter optimization of the composites for the both tribological loading conditions. Two "control parameters" were varied (namely, the filler content and the type of the coupling agent), so it was required to choose the ranking principle according to the second condition. The authors aimed to increase the adhesion level. Hence, yield strength was chosen as a mechanical property proportional to it. The authors understood a certain convention of this approach, but did not have other quantitative experimental data that could be directly measured. Moreover, since it also depended on the amount of the filler, the yield strength value was used that had been found at the maximum filling degree of $23 \mathrm{wt} . \%$.

Then, the surface drawing method of the mechanical and tribological properties was used by analogy with the approach proposed in [49]. The wollastonite content and the yield strength values of the "UHMWPE + 23 wt. \% wollastonite" composites (both untreated and silanized with the coupling agents) were used as control parameters. It should be noted that yield strength was lower after treatment with the "OTS" coupling agent than for the composite with untreated wollastonite. As a result, such a composite was listed lower than untreated one when ranking by this parameter. As noted above, this was due to both the high level of mechanical adhesion of wollastonite fibers and, most likely, the negative effect of the "OTS" coupling agent on the composite structure formation. 


\subsection{Computational Design of the UHMWPE-Based Composite for the "Moderate" Conditions of the Metal-Polymer Tribological Loading}

Initially, a range of the physical and mechanical properties was predefined for the composite intended for use in the metal-polymer units under the "moderate" conditions of tribological loading. This provided for a long-term operation with a low level of volumetric wear. The authors primarily focused on the mechanical and tribological properties of neat UHMWPE as baseline values. Below is the rationale for their choice.

The long-term operation and, accordingly, continuous loading implied the ability to withstand high static loads. For this reason, an elastic modulus above $1050 \mathrm{MPa}$ was chosen, which was $350 \mathrm{MPa}$ higher than that of neat UHMWPE.

Tensile strength of the composites was mainly determined by the possibility of their deformation. This was almost proportional to elongation at break under tensile loads. Since the loading type in the tribological units did not provide for such a high material strains, a tensile strength value above $30 \mathrm{MPa}$ was adopted as a threshold level. This corresponded to a strain value of neat UHMWPE at a stress of about $300 \%$.

Based on the same considerations, the elongation at break value was assumed to be $300 \%$. This was $37 \%$ less than that of neat UHMWPE. However, the achievement of such a strain level was a clear indicator of the structure homogeneity and the composite viscosity.

An increase in strength of the composites by reinforcement was typically accompanied by a decrease in their impact toughness (as characteristics of dynamic fracture toughness). The Charpy impact toughness value of neat UHMWPE was $A_{\mathrm{K}} \geq 150 \mathrm{~kJ} \cdot \mathrm{m}^{-2}$ (without fracture). Since such (dynamic) loads were rare under the operating conditions of the metal-polymer tribological units, the authors considered taking the $A_{\mathrm{K}} \geq 90 \mathrm{~kJ} \cdot \mathrm{m}^{-2}$ value as a threshold level. This was $60 \%$ lower than that of neat UHMWPE, but higher than even a perfectly acceptable two-fold decrease $A_{K} \geq 75 \mathrm{~kJ} \cdot \mathrm{m}^{-2}$.

The friction coefficient value did not particularly affect wear resistance under the "moderate" conditions of tribological loading, when wear was mainly "controlled" by the fatigue mechanism (in this case, heating of the contacting parts was negligible). Therefore, 0.12 was chosen as a threshold value of the friction coefficient, which was only 0.02 higher than that of neat UHMWPE.

From the point of view of setting the threshold level, the most critical was the wear rate parameter (namely, "net" wear, measured considering elastic recovery according to the "block-on-ring" scheme under the "moderate" conditions). This was chosen equal to that of neat UHMWPE, since it was the properties of pure polymer that was required to be surpassed. For this reason, the wear factor $(\mathrm{WF}) \leq 0.49 \times 10^{-6} \mathrm{~mm}^{3} \cdot \mathrm{N}^{-1} \cdot \mathrm{m}^{-1}$ condition was predefined.

The surfaces of the tribomechanical properties were drawn on the basis of the previously obtained experimental data and assigned threshold levels (Figure 14). 


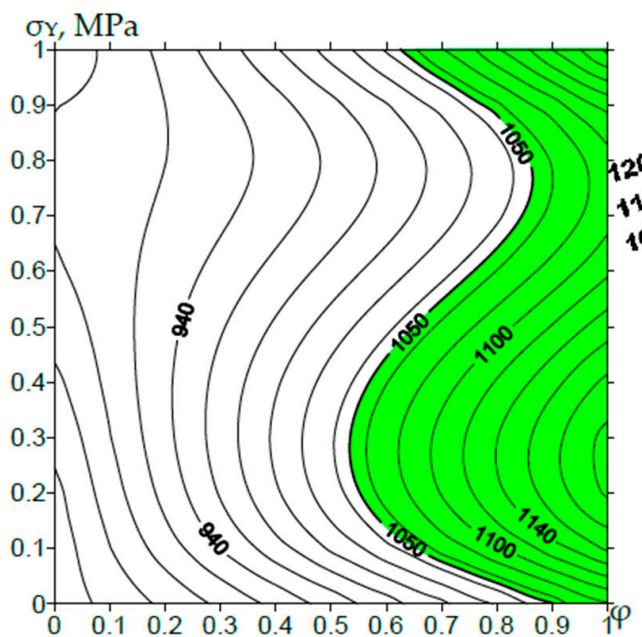

(a)

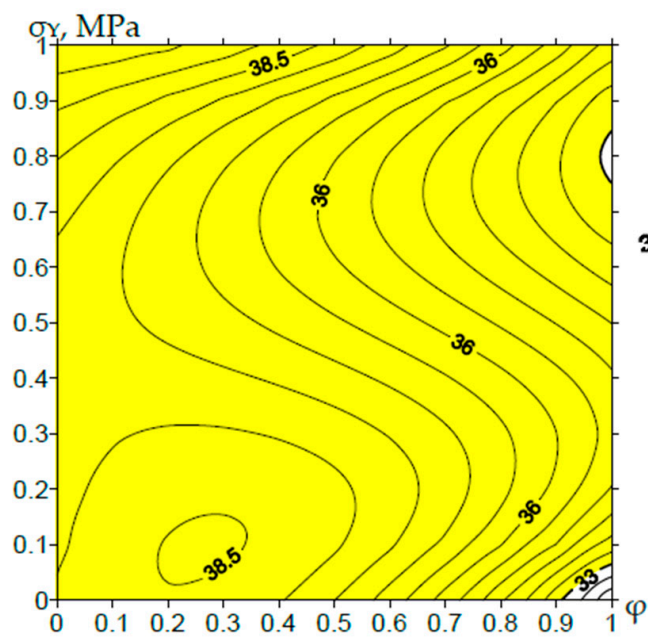

(c)

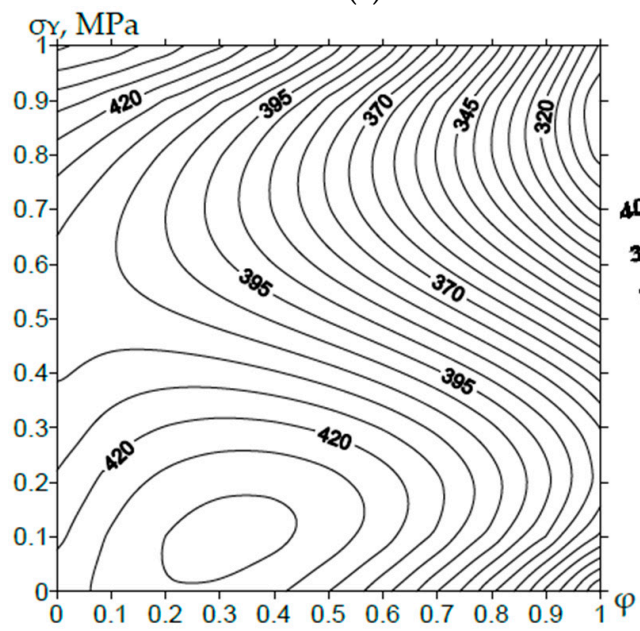

(e)

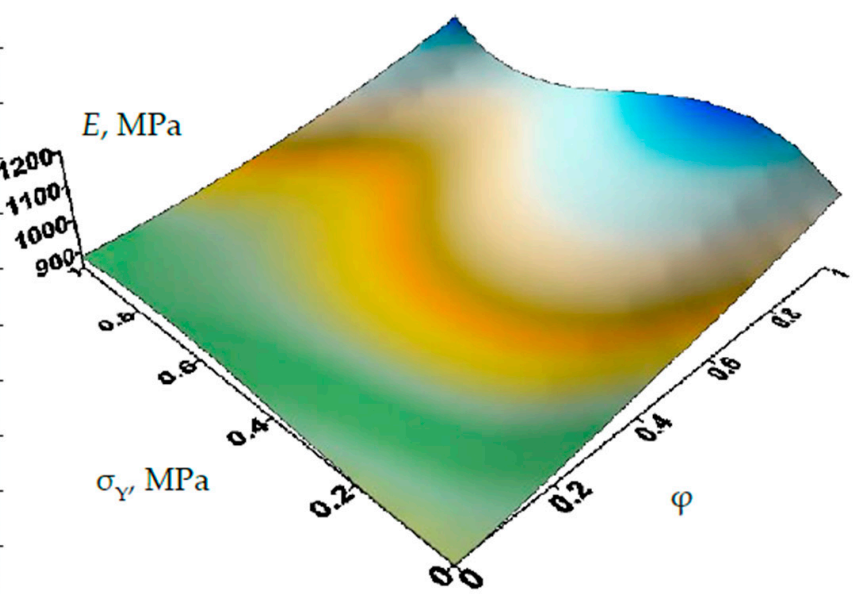

(b)

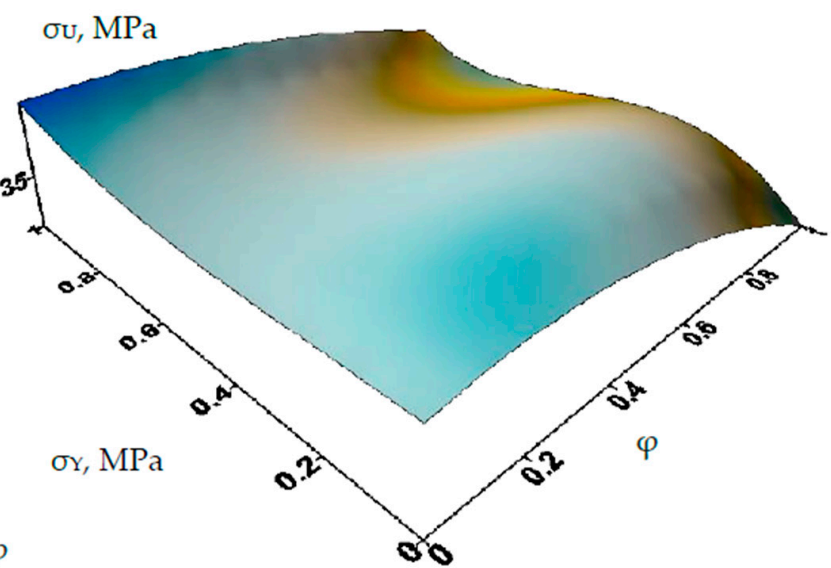

(d)

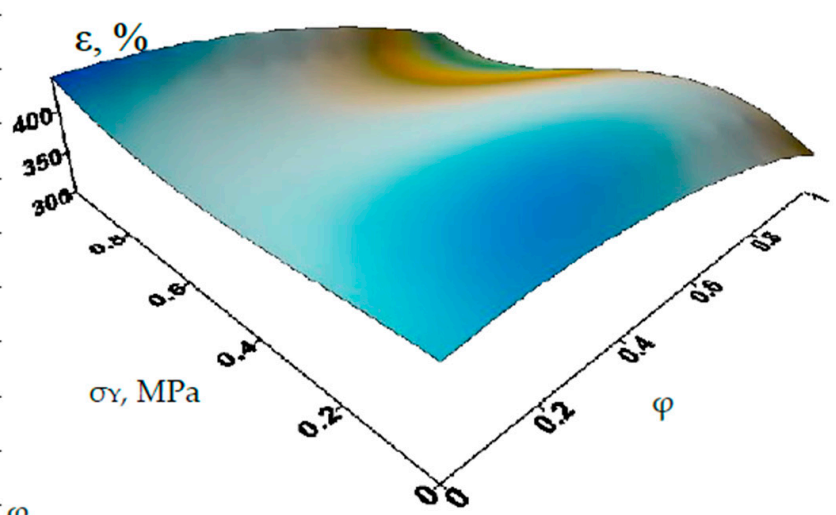

(f)

Figure 14. Cont. 


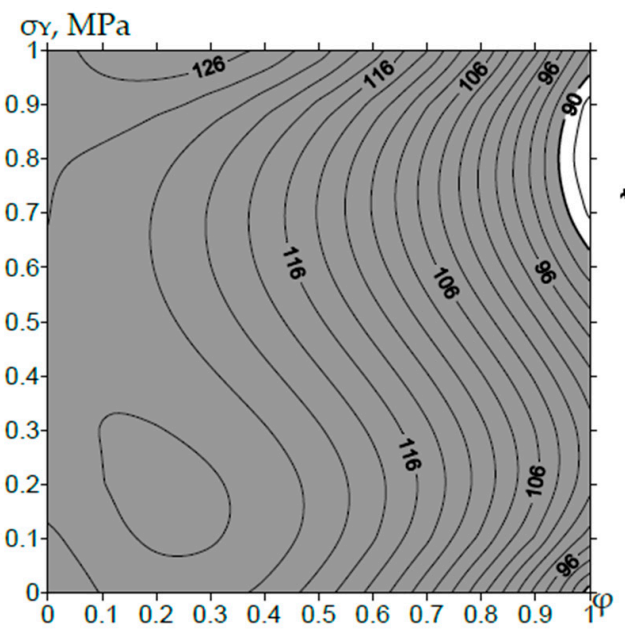

(g)

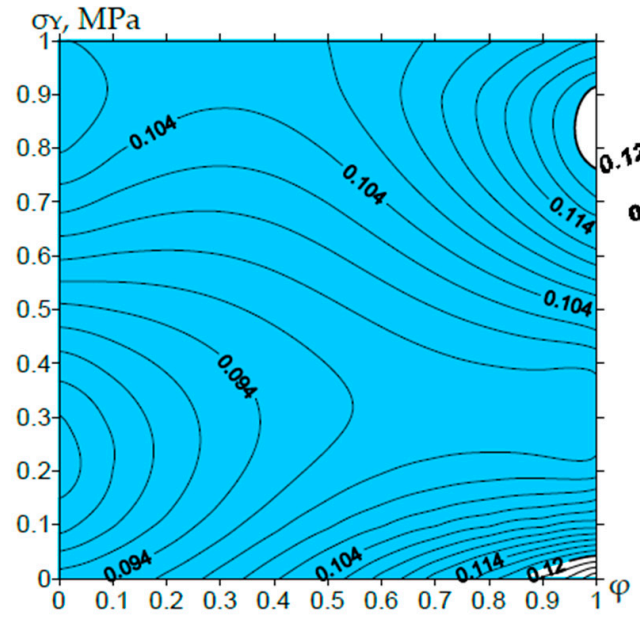

(i)

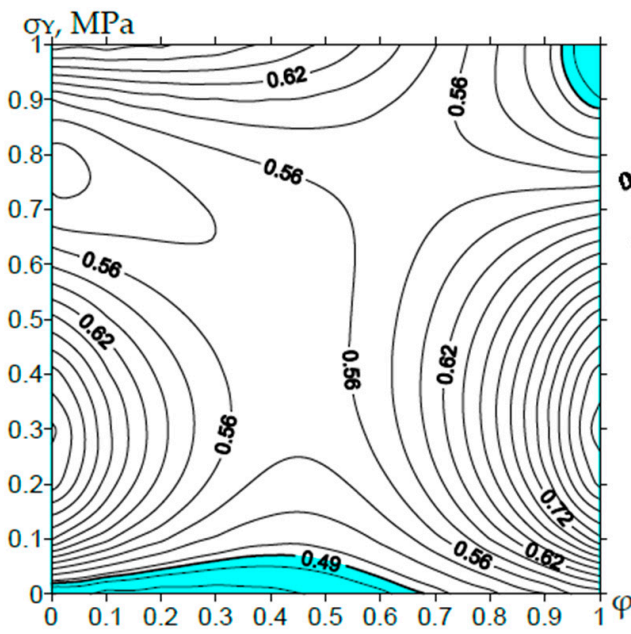

(k)

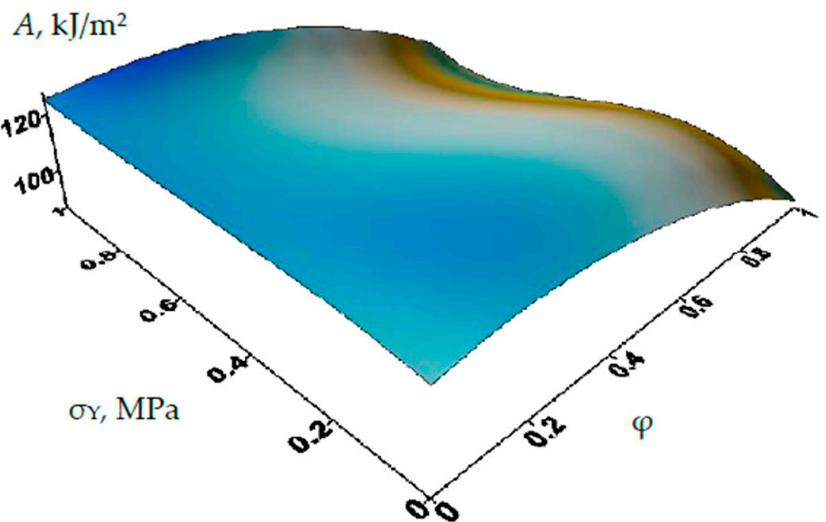

(h)

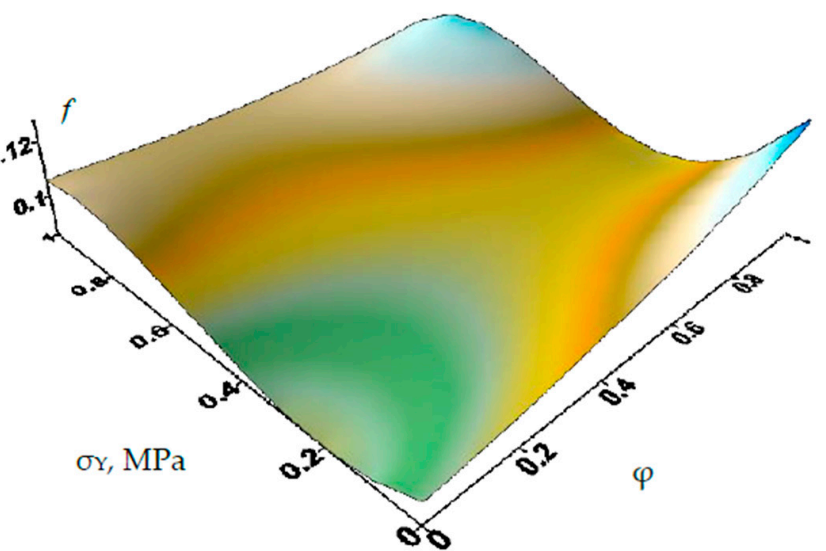

(j)

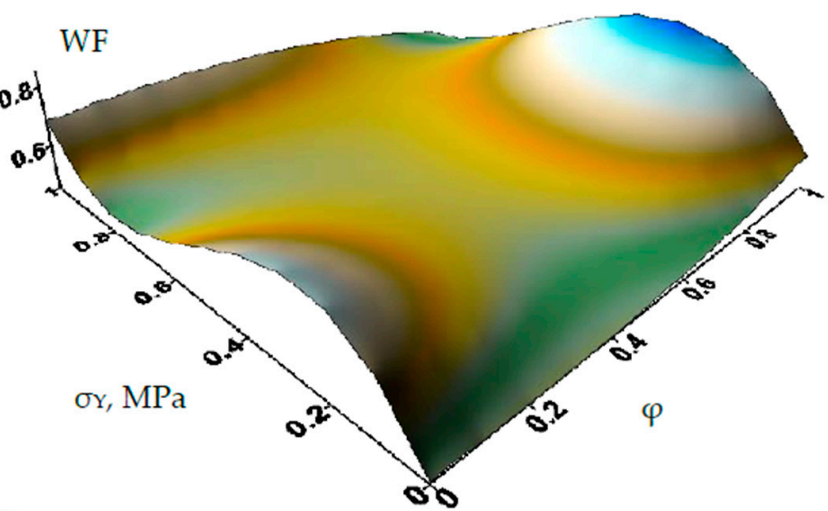

(1)

Figure 14. Isoline patterns on the operational properties of the UHMWPE-based composites: elastic modulus $E, \mathrm{MPa}(\mathbf{a}, \mathbf{b})$; ultimate tensile strength $\sigma_{\mathrm{U}}, \mathrm{MPa}(\mathbf{c}, \mathbf{d})$; elongation at break $\varepsilon, \%$ (e,f); impact toughness $a_{\mathrm{k}}, \mathrm{kJ} \cdot \mathrm{m}(\mathbf{g}, \mathbf{h})$; the friction coefficient $f(\mathbf{I}, \mathbf{g})$; and wear rate $\mathrm{I}, 10^{-6} \mathrm{~mm}^{3} \cdot \mathrm{N}^{-1} \cdot \mathrm{m}^{-1}(\mathrm{Load}=140 \mathrm{~N}$, Velocity $\left.=0.5 \mathrm{~m} \cdot \mathrm{s}^{-1}\right)(\mathbf{k}, \mathbf{l})$. 
The range of the control parameters ensuring the correspondence of the tribomechanical properties of the material to the given boundaries is shown in Figure 15. Only a small region in the upper right corner filled in green satisfied all predefined requirements. It corresponded to the maximum both filler content of $23 \mathrm{wt}$. \% and yield strength (with the same filling degree) of $25.4 \mathrm{MPa}$. It should be noted that not all material properties used in the analysis had an effect on the region formation.

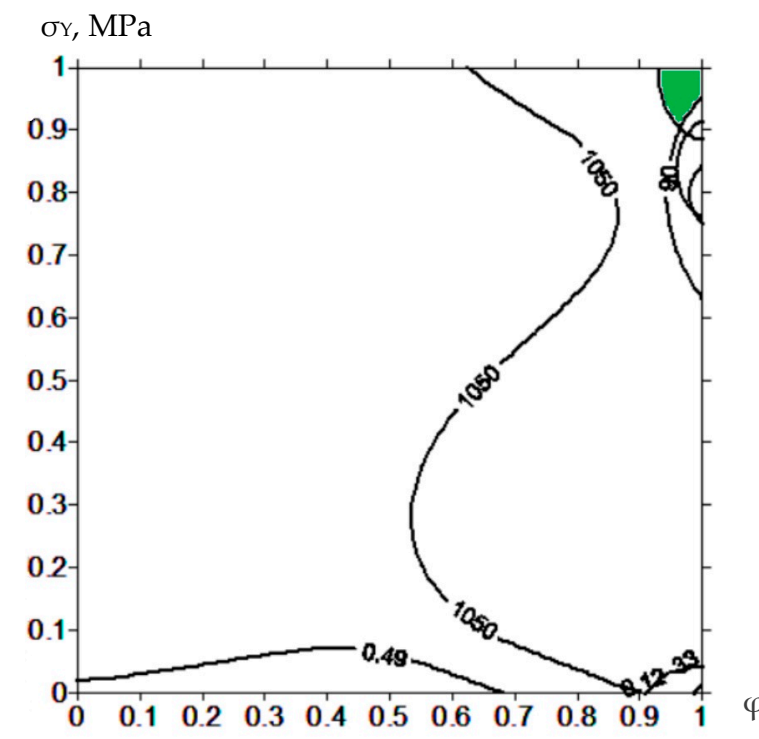

Figure 15. The range of the control parameters that ensure the physical and mechanical properties of the composites meet the specified limits for the "moderate" conditions of the metal-polymer tribological loading.

This was evidenced by a fairly small number of isolines limited it. In addition, a region limited on all sides would be more convincingly obtained in terms of the composite design. Highly likely in this case that a further increase in the filler content was useful to achieve (and possibly even exceed) the required levels of the threshold values. However, the experimental data analysis unequivocally testified to the fact that an increase in the wollastonite content over $23 \mathrm{wt} . \%$ was impractical, since the composite structure, as well as the mechanical and tribological properties worsened.

\subsection{Computational Design of the UHMWPE-Based Composite for the "Severe" Conditions of the Metal-Polymer Tribological Loading}

In this section, the threshold values of the tribomechanical properties of the UHMWPE-based composite loaded with $10 \mathrm{wt}$. \% wollastanite were predefined for use in the "severe" conditions of the metal-polymer tribological loading. This implied both an increase in load and a high level of wear rate. The authors showed above that polymer wear was accompanied by the low level of reversible strains in this case. This was due to the following reasons: (i) an increase in temperature; (ii) a decrease in specific pressure; and (iii) rising volumetric wear and, accordingly, reducing the amount of the material capable to elastic recovery. In this regard, the elastic modulus threshold value of $950 \mathrm{MPa}$ was predefined. This was $250 \mathrm{MPa}$ higher than that of neat UHMWPE, but $100 \mathrm{MPa}$ lower than that for the "moderate" conditions of the metal-polymer tribological loading.

Initially, it was assumed that the composite was subjected to intense strains and subsequent failure under the "severe" conditions of the metal-polymer tribological loading. Therefore, the requirements for tensile strength were increased and a threshold value of $35 \mathrm{MPa}$ was adopted. This was the neat UHMWPE stress level at a strain rate of $400 \%$.

The threshold level for elongation at break of 350\% was increased relative to the "moderate" conditions according to similar assumptions. This was $27 \%$ less than that of neat UHMWPE. As in the 
previous case, the achievement of such a strain level was a clear indicator of the structure homogeneity and the composite strain stability.

The regular impact loads were also unlikely under the "severe" conditions of the metal-polymer tribological loading. However, local impacts could be due to removing material as well. For this reason, the impact toughness threshold was raised up to $A_{\mathrm{K}} \geq 100 \mathrm{~kJ} \cdot \mathrm{m}^{-2}$, which was $50 \mathrm{~kJ} \cdot \mathrm{m}^{-2}$ below that of neat UHMWPE.

Under the "severe" conditions of the metal-polymer tribological loading, the material wear was already "controlled" by adhesive processes, as well as oxidation, and plasticization due to the frictional heating. Therefore, the requirements for the friction coefficient value had to be slightly increased. The threshold level was predefined at 0.11, which was slightly less than that of neat UHMWPE.

As in the previous case, the most critical was the wear rate parameter. In order to simultaneously improve the mechanical and tribological properties of the composite, the value was taken at $\mathrm{WF} \leq 2.25 \times 10^{-6} \mathrm{~mm}^{3} \cdot \mathrm{N}^{-1} \cdot \mathrm{m}^{-1}$, which was $25 \%$ lower than that of neat UHMWPE.

The surfaces of the mechanical and tribological properties with the distinguished levels of their threshold values are shown in Figure 16.

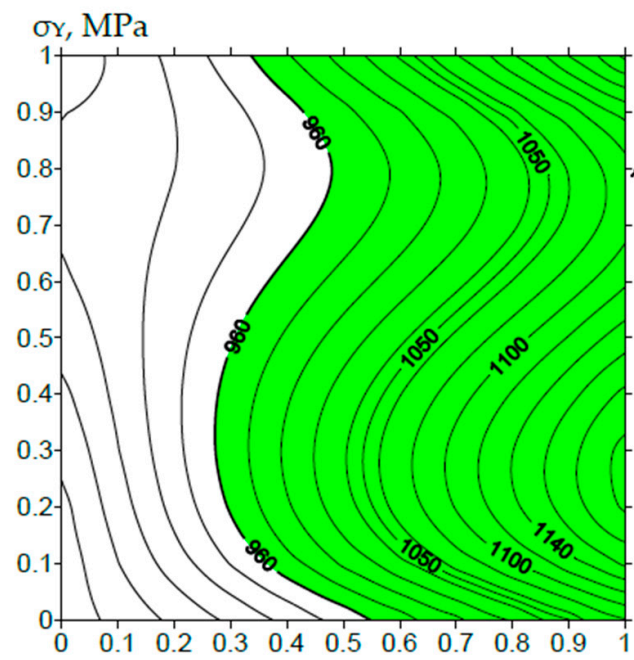

(a)

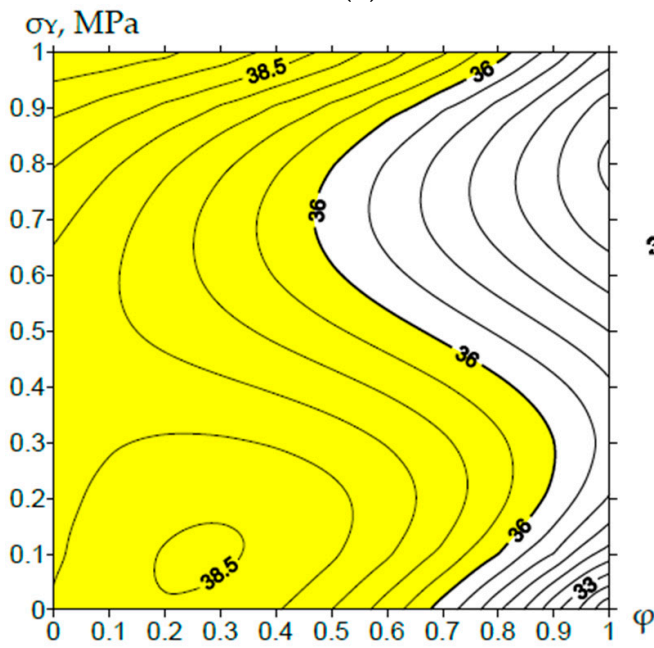

(c)

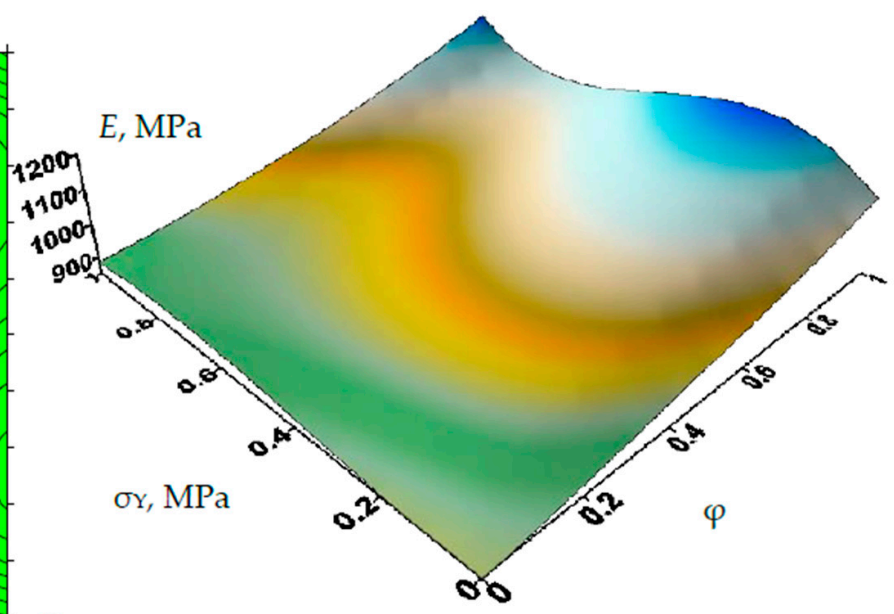

(b)

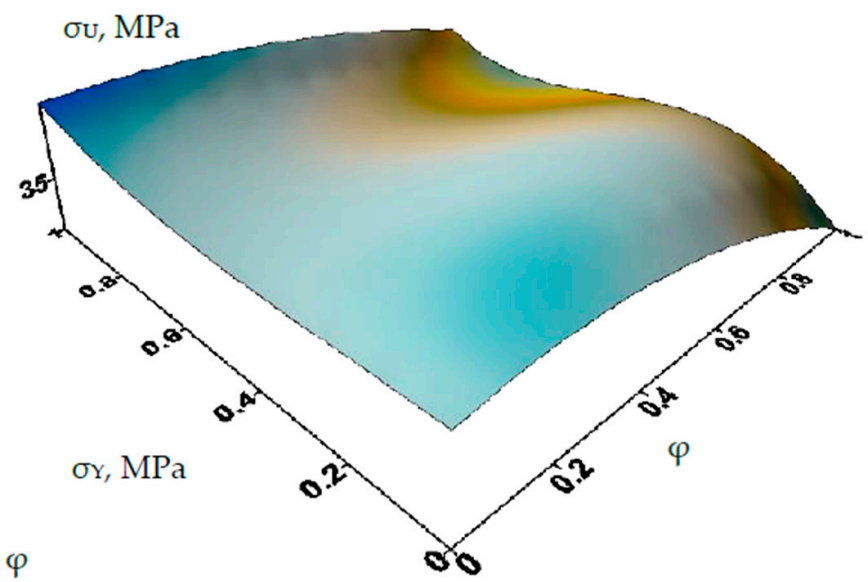

(d)

Figure 16. Cont. 


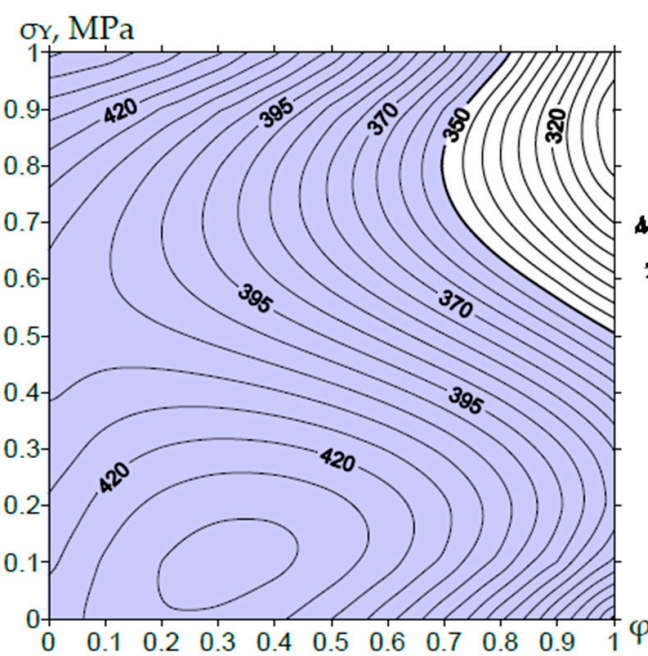

(e)

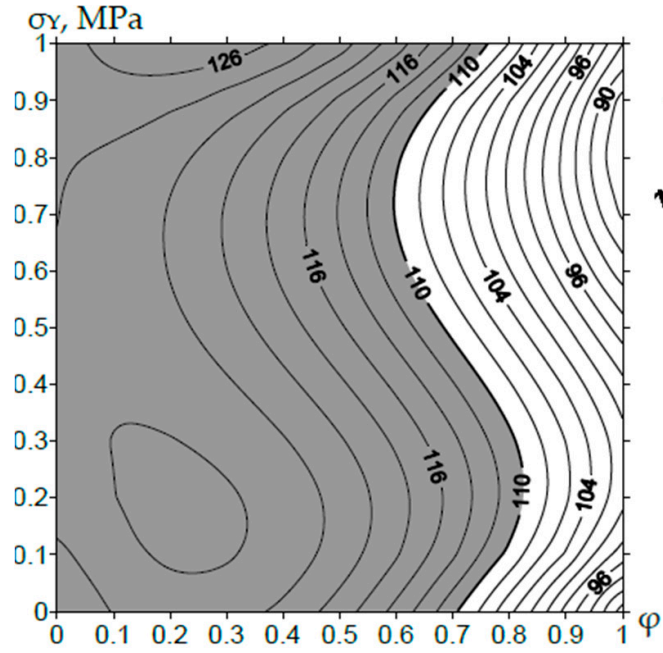

(g)

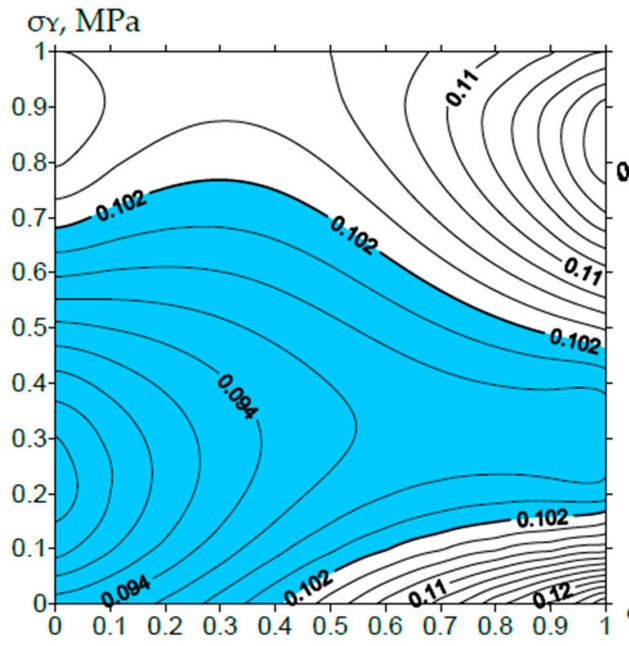

(i)

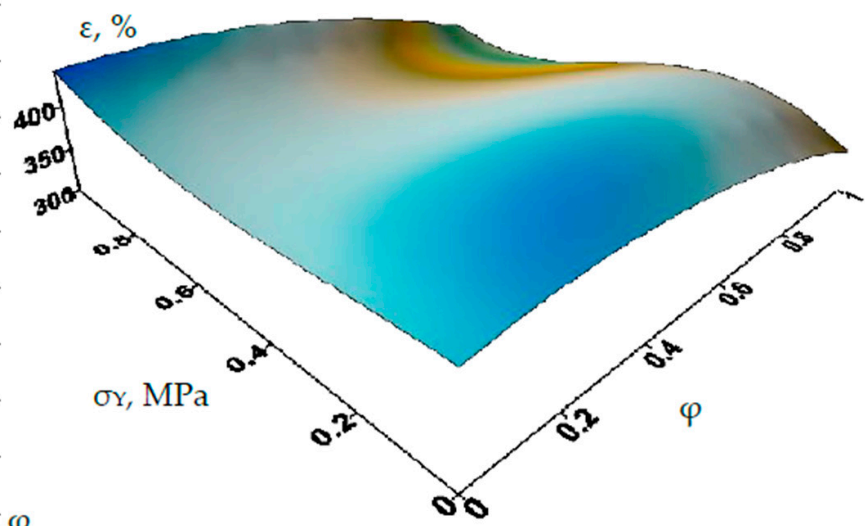

(f)

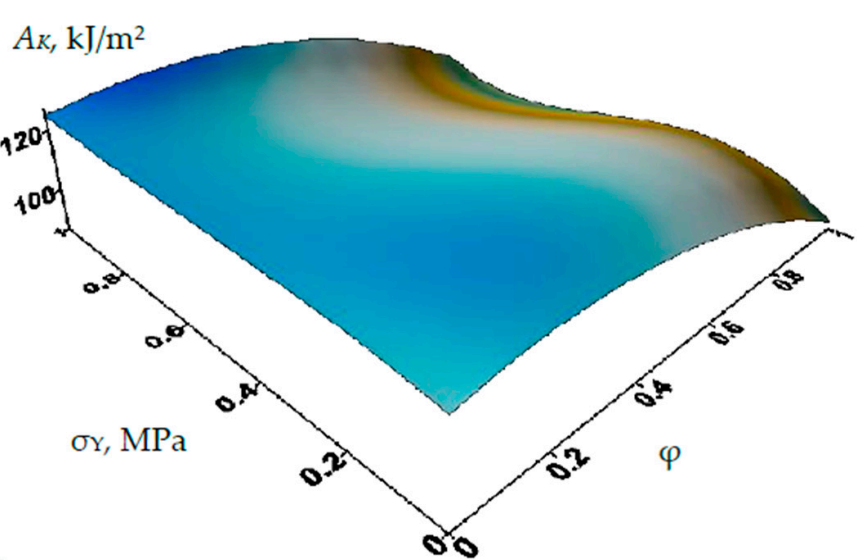

(h)

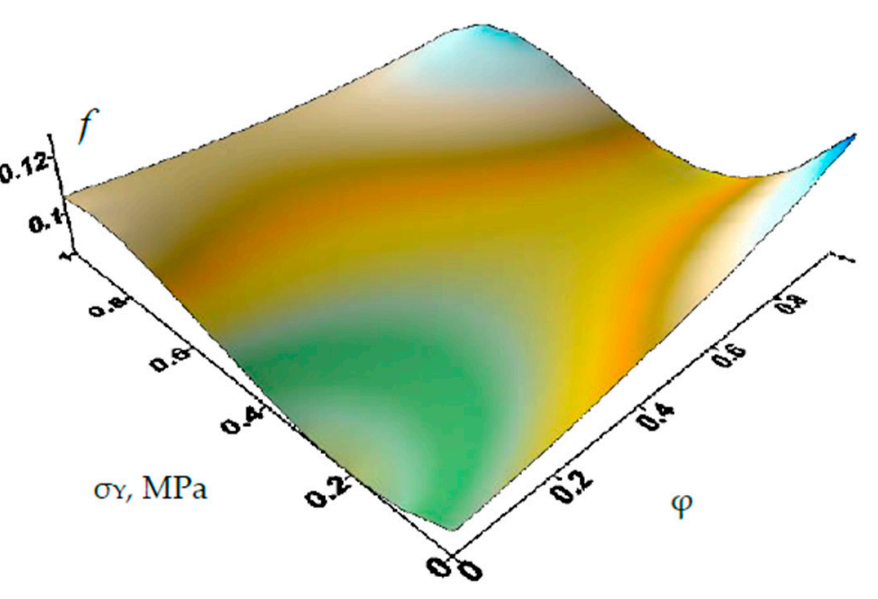

(j)

Figure 16. Cont. 


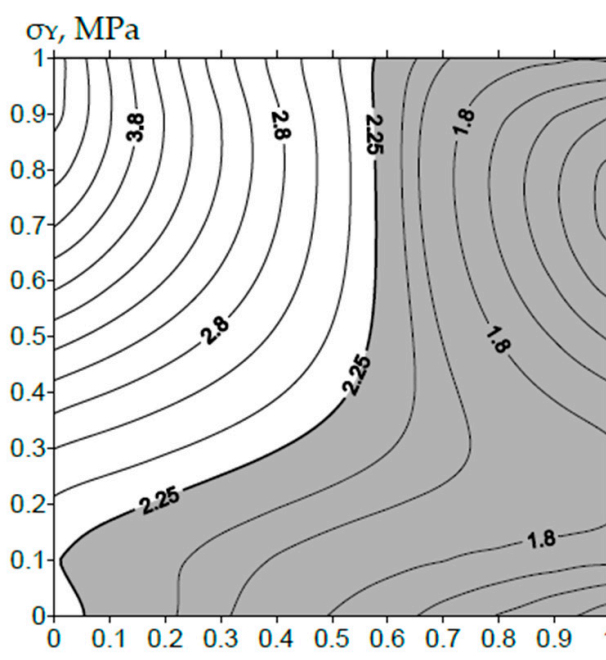

(k)

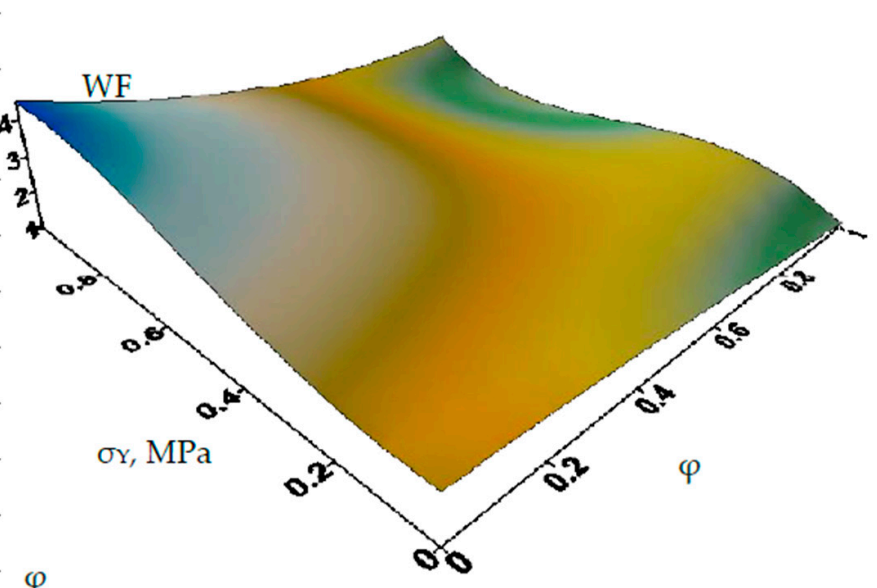

(1)

Figure 16. Isoline patterns on the operational properties of the UHMWPE-based composites: elastic modulus $\mathrm{E}, \mathrm{MPa}(\mathbf{a}, \mathbf{b})$; ultimate tensile strength $\sigma_{\mathrm{U}}, \mathrm{MPa}(\mathbf{c}, \mathbf{d})$; elongation at break $\varepsilon, \%$ (e,f); impact toughness $\mathrm{a}_{\mathrm{k}}, \mathrm{kJ} / \mathrm{m}(\mathbf{g}, \mathbf{h})$; the friction coefficient $f(\mathbf{i}, \mathbf{g})$; and wear rate $\mathrm{I}, 10^{-6} \mathrm{~mm}^{3} \cdot \mathrm{N}^{-1} \cdot \mathrm{m}^{-1}(\mathrm{Load}=140 \mathrm{~N}$, Velocity $\left.=0.5 \mathrm{~m} \cdot \mathrm{s}^{-1}\right)(\mathbf{k}, \mathbf{l})$.

An area of the control parameter values ensuring the correspondence of the mechanical and tribological properties of the composite to the given boundaries is shown in Figure 17. In this case, the region filled in green was bounded on all sides. This enabled to design the composite more reliably. However, an important result was the fact that only composites with untreated wollastonite were in the range of the acceptable values. The range of their content could be quite high from 11.8 up to $19.8 \mathrm{wt}$. \%. It should be noted once again that no composites loaded with silanized fibers was in the filled region.

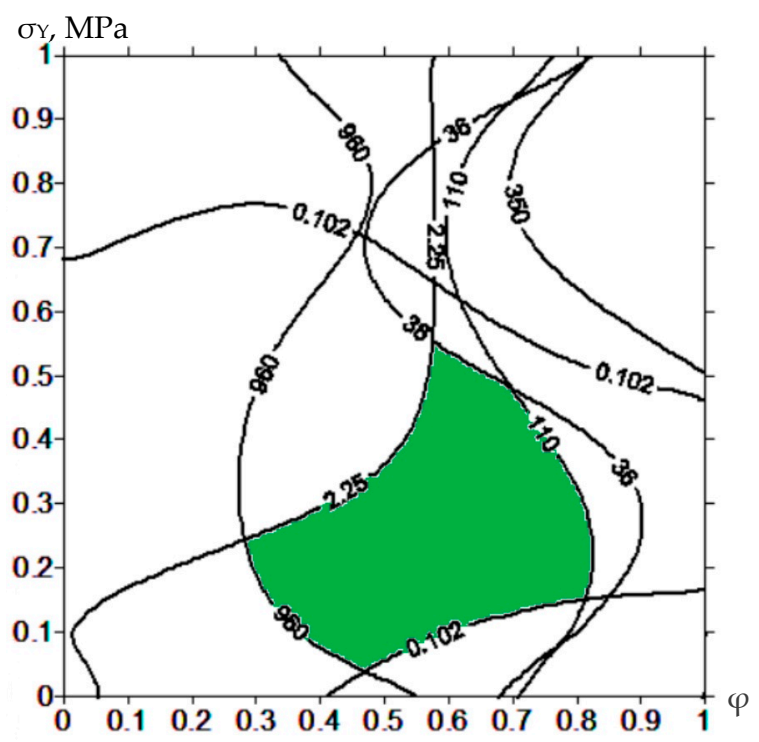

Figure 17. The range of the control parameters that ensure the physical and mechanical properties of the composites meet the specified limits for the "severe" conditions of the metal-polymer tribological loading.

Thus, the structure and the tribomechanical properties of the UHMWPE-based composites with a variable adhesion level due to the wollastonite silanization were analyzed during these studies. 
Based on the obtained results, the most suitable composites were recommended for operation in the metal-polymer tribological loading units under the "moderate" and "severe" conditions.

It was discussed that the positive role of increasing adhesion between the polymer matrix and the filler could not be largely identified and shown due to the initially high level of mechanical adhesion. This was because of wollastonite fiber complex shapes, which enabled the polymer to fit and hold firmly under mechanical and tribological loading. On the other hand, wollastonite microfibers had a relatively short length (up to $60 \mu \mathrm{m}$ ). As a result, it was not possible to significantly improve the strength properties even by increasing interfacial adhesion.

In addition, the presence of the coupling agent in the composites enabled both local structure deterioration and change in the development of the tribological processes. The deterioration of the tribological properties could be associated with this issue for a number of compositions and loading modes. The silanization made it possible to significantly improve both the mechanical and tribological properties when using fibers of a significantly longer length (units of millimeters and above) [42].

\section{Discussion}

Wollastonite, being a mineral and an inexpensive filler, is widely applied in many industries for filling polymer matrixes. In general, this enables to improve both their strength properties and wear resistance, including abrasion [36,39]. In these studies, two issues have been simultaneously solved: (1) to enhance the mechanical properties of the UHMWPE-based composites loaded with wollastonite by increasing the interfacial adhesion level and (2) to evaluate the effect of the adhesion level (and the coupling agent type) on wear resistance under the dry sliding friction conditions. The discussion of the obtained results has been presented in the same order.

Loading with wollastonite in the studied content range (up to $23 \mathrm{wt}$ \%) did not significantly affect the strength properties (no multiple changes occurred), since the length of individual fibers did not exceed tens of microns that was less than the size of separate spherulites. In addition, the aspect ratio of wollastonite fibers did not exceed 10. Therefore, the filler gave rise to the dispersed hardening mechanism than to the reinforcing one.

It is known that a great contribution to the improvement of the strength properties of the polymer composites could be made by loading with fibers several millimeters (or more) in length. In this case, the significant increase in their both the elastic modulus and yield strength was possible due to the enhanced interfacial adhesion. The reason was that load was transferred to the greater degree (and simultaneously over the large space) from the polymer matrix to reinforcing fibers [50].

Additional features of wollastonite fibers were their needle-like shapes and rather developed surfaces. Microfibers, being tightly pressed into the UHMWPE matrix, were mechanically strongly coupled to it, although they did not possess any chemical bonds. As the obtained results showed, both their small length and additional loading with the coupling agents did not cause any drastically improvements of the strength properties. Nevertheless, certain distinctions between the applied coupling agents (in terms of yield strength) were observed. The reason was various mechanisms of their effects.

From the standpoint of the action principle, each silane-containing coupling agent was characterized by the presence of two active groups. One of them was able to form new chemical bonds with the mineral filler, while the other provided adhesion to the polymer matrix. In the second case, such a relationship could be either chemical or physical in nature [51-53]. For UHMWPE (precisely because of its chemical inertness), loading with the silane-containing coupling agents could form only physical bonds (Van der Waals forces). In [54,55], the mutual diffusion concept was applied to explain the reasons for the formation of the bonds between the silane-containing coupling agent and polyolefin (in this case, UHMWPE).

Among the silane-containing coupling agents used in these studies, the "KH-550" one was recognized as the most effective, since it enabled the formation of new chemical bonds with the mineral filler. This was evidenced by the (Si-O) peaks in the IR spectra (Figure 5). In the previous author's 
studies of the UHMWPE-based composites [42], the functionalization of the fibrous filler with the "KH-550" coupling agent made it possible to improve their mechanical properties and wear resistance. According to both the obtained results and the published data, the "KH-550" coupling agent was characterized by the high chemical activity. Therefore, it was able to provide the maximum adhesion to the mineral filler.

The "OTS" coupling agent possessed the longest non-polar chemical group (octadecyl). In accordance with the mutual diffusion concept, this caused the increase in the adhesion of the coupling agent to the UHMWPE matrix (since both octadecyl and UHMWPE possessed the - $\left.\left(\mathrm{CH}_{2}-\mathrm{CH}_{2}\right)_{\mathrm{n}}-\mathrm{CH}_{3}\right)$ nonpolar chemical chain). These similar chemical structures penetrated one another more efficiently and facilitated the forceful diffusion of the "OTS" coupling agent into the long molecular chains of UHMWPE. The "Penta-1006" one was a polyorganosiloxane. It also included many nonpolar chemical groups, in particular methyl $\left(-\mathrm{CH}_{3}\right)$ and ethyl $\left(-\mathrm{C}_{2} \mathrm{H}_{5}\right)$. In terms of efficiency, they could be ranked first by the "KH-550" coupling agent and then the "OTS" one. This fact was consistent with the mechanical test results both obtained in these studies and published in [42].

Thus, in full accordance with the concept of E.P. Plueddemann [56], who stated that "Wetting studies on silane-treated glass are futile in arriving at a coupling agent adhesion mechanism since the interface between coupling agent and resin disappears during preparation of the composite. The only interface of significance is that between the silanol-modified polymer surface and the mineral. ... In preparing a composite of a hydrophilic mineral surface and an organic polymer it is obvious that the organic phase must make intimate contact with the mineral surface as proposed by older theories of adhesion.... A new working theory of adhesion at the polymer-mineral interface is now proposed in which silane coupling agents provide a bond at the interface that is capable of using the hydrolytic intrusion of water, with self-healing, as a means of stress relaxation without disrupting the overall bond between plastic and mineral surface. Such a reversible hydrolytic bond mechanism controlled by equilibrium conditions accounts for all the observed phenomena of adhesion to hydrophilic surfaces through silane coupling agents.", the "KH-550" coupling agent had to be considered as the most effective one. It improved adhesion to wollastonite fibers due to the maximum chemical activity. The "OTS" and "Penta-1006" ones provided higher adhesion of the coupling agents to the UHMWPE matrix because of longer molecules. This also solved the compatibility issue, but less efficiently than in the case of the "KH-550" coupling agent.

The following is the discussion of the results of the tribological tests. It was shown for neat UHMWPE [26] that reorientation of molecules was observed in the surface layer along the dry sliding friction direction. This process increased wear resistance of neat UHMWPE. However, after loading fillers into the polymer matrix, several other processes had to affect its wear:

- Protruding onto the friction surface, filler fibers took on part of the load and changed the nature of the tribological interaction of both parts in the friction pair.

- The composites were more durable and less deformed under the load transferred from the counterpart due to the reinforcement effect.

- In the case of fiber break on the friction surface, debris could exert the abrasive effect causing the increase in wear rate.

- Under the severe conditions of tribological loading, when the contact temperature increased, reinforcing fibers were able to restrain the plastic flow of the plasticized material improving wear resistance.

- In the case of low hardness and/or chipping of the filler, it gave the polishing effect on both the counterpart and the friction surface of the polymer composites that also contributed to the decrease in wear rate.

The key objective of loading with coupling agents was to improve the strength properties through enhanced adhesion. Therefore, in addition to the factors mentioned above, this gave the following effects: 
- prevented debris removal and reduced abrasive wear of the components due to better retention of fibers in the polymer matrix;

- $\quad$ reduced wearing the polymer matrix and breaking fibers by tensile loads due to higher strength and less strains of the composites;

- decreased stress gradients at the interface between the filler and the polymer due to the formation of a transition layer between them; and

- deteriorated the polymer matrix and, accordingly, the mechanical and tribological properties of the composites due to the complex chemical structure.

The results of the analysis of the mechanical test data (Tables 1-4) were consistent with the latest statement. Loading with the "OTS" coupling agent reduced yield strength of the "UHMWPE $+23 \%$ wollastonite" composite compared to that of the untreated one. It could also be the cause of the ambiguous change in wear resistance as a function of the silanization efficiency.

Despite the fact that the "UHMWPE + 23 wt. \% wollastonite + KH-500" and "UHMWPE + 15 wt. \% wollastonite" composites were recommended according to Sections 3.3 and 3.4 for use under the moderate and severe conditions of tribological loading, respectively, these compositions had been designed by summarizing all the tribological, mechanical, and physical properties considered by the computer algorithm. It should be noted that the designed composite really possessed the minimal wear rate under the moderate conditions of tribological loading, while the "UHMWPE $+23 \mathrm{wt} . \%$ wollastonite + Penta-1006" and "UHMWPE + 23 wt. \% wollastonite + OTS" composites were the best ones for the severe conditions. They were not characterized by the maximum yield strength (compared to that of the "UHMWPE + $23 \mathrm{wt}$. \% wollastonite + KH-500" composite). In most cases of the moderate and severe tribological conditions, loading with the "OTS" coupling agent was accompanied by the minimal wear rate at almost all filling degrees. This conclusion was based on the results of the comparison of the data presented in Figure 7.

However, in addition to the contribution of each coupling agent to the interfacial adhesion value, their different chemical nature also affected the polymer matrix structure. Therefore, it was impossible to unambiguously interpret the "adhesion-wear resistance" correlation according to the obtained results. Moreover, this relationship was not the same under the moderate and severe conditions of tribological loading.

Further, the authors stated that the maximum wollastonite content had to be $23 \mathrm{wt}$. $\%$ as the key condition for the summarized interpretation of the tribological test data (first of all, according to the criterion of the maximum increase in the strength properties without considering the decrease in impact strength). In the framework of this formulation, loading with all the studied coupling agents made it possible to improve wear resistance under the moderate conditions of tribological testing with respect to untreated wollastonite fibers (Figure 7a). The minimal wear rate was characteristic of the most effective "KH-550" coupling agent (although these composites and neat UHMWPE possessed close wear rate values of approximately $\left.0.49 \times 10^{-6} \mathrm{~mm}^{3} \cdot \mathrm{N}^{-1} \cdot \mathrm{m}^{-1}\right)$. In this case, wear rate was calculated considering the elastic recovery, namely, $24 \mathrm{~h}$ after the end of the tribological tests (it was equal to approximately $1.34 \times 10^{-6} \mathrm{~mm}^{3} \cdot \mathrm{N}^{-1} \cdot \mathrm{m}^{-1}$ immediately after the tests). It should be noted that wear rate was slightly higher than $0.57 \times 10^{-6} \mathrm{~mm}^{3} \cdot \mathrm{N}^{-1} \cdot \mathrm{m}^{-1}$ for the least active "OTS" coupling agent.

It follows from the analysis of the photographs in Figure 10 that the minimal wear rate was accompanied by the formation of the smoother wear track surfaces (Figure 10c,e) with such significant wollastonite content ( $23 \mathrm{wt} . \%$ ) in UHMWPE compared with that of neat polymer (Figure 10a). Perhaps, the reason was its polishing with debris (including chipped wollastonite particles). For neat UHMWPE, wear was more of the fatigue-adhesive nature that did not give a decisive effect assuming that the more effective "KH-550" coupling agent made it possible to hold the filler more firmly under the moderate conditions of tribological loading. However, the surface of the composite loaded with the untreated filler (Figure 10b) looked rougher. Chipped wollastonite was able to significantly reduce wear resistance of the "UHMWPE + $23 \mathrm{wt}$. \% wollastonite" composite (its wear rate was about $\left.0.85 \times 10^{-6} \mathrm{~mm}^{3} \cdot \mathrm{N}^{-1} \cdot \mathrm{m}^{-1}\right)$. 
Under the severe conditions of tribological testing, all composites with the filling degree of $23 \mathrm{wt}$. \% showed wear rate lower than that of neat UHMWPE (which wear rate was approximately $\left.3.05 \times 10^{-6} \mathrm{~mm}^{3} \cdot \mathrm{N}^{-1} \cdot \mathrm{m}^{-1}\right)$. Moreover, the minimum wear rate of $1.0-1.1 \times 10^{-6} \mathrm{~mm}^{3} \cdot \mathrm{N}^{-1} \cdot \mathrm{m}^{-1}$ was observed (Figure $7 \mathrm{~b}$ ) precisely with less adhesion (the "Penta-1006" and "OTS" coupling agents). Nevertheless, both the complete absence of any chemical bonds and the maximum adhesion with the "KH-550" coupling agent were accompanied by the same (or higher) wear rates of about $2.0 \times 10^{-6} \mathrm{~mm}^{3} \cdot \mathrm{N}^{-1} \cdot \mathrm{m}^{-1}$. The important addition to this result was the counterpart temperature measurement data presented in Table 6 . The maximum wear rate of neat UHMWPE (approximately $3.05 \times 10^{-6} \mathrm{~mm}^{3} \cdot \mathrm{N}^{-1} \cdot \mathrm{m}^{-1}$ ) was accompanied by the higher heating of the steel counterpart up to $57.3^{\circ} \mathrm{C}$. Also, plasticized material creases were observed on the wear track surface (Figure 13a).

It should be noted that the similar patterns of creases were the characteristic of the wear track surfaces of the "UHMWPE + 7 wt. \% wollastonite" composites (Figure 11) regardless of the presence and the type of the coupling agents. However, the roughest wear track surface was on the composite loaded with untreated wollastonite (Figure 13b) for the analyzed maximum filler content. It was slightly smoother on the composite loaded with the "KH-550" coupling agent, and the smoothest wear track surface was on the one filled with the "Penta-1006" and "OTS" coupling agents. For the last two cases, both the minimal wear rates and the lower temperatures of the steel counterpart were observed (43.2 and $47.6^{\circ} \mathrm{C}$, respectively).

According to the authors, the decrease in wear rate for the "less effective" coupling agents compared to that of neat UHMWPE more than two times was probably due to their more complex chemical composition (in particular, Figure 5 shows that the peaks were in the range of the inverse wavelengths of 1028-1090 $\mathrm{cm}^{-1}$, confirming the efficiency of the coupling agents). Under the severe conditions of tribological loading (which was accompanied by the increase in temperature), the above ability of the "OTS" and "Penta-1006" coupling agents to better interact with UHMWPE molecules could both reduce the intensity of the oxidation processes [34] and facilitate sliding the steel counterpart on the composite surfaces.

In the case of the most effective "KH-550" coupling agent (and when it was absent at all), mechanical adhesion between the initial (untreated) polymer matrix or the one modified with a coupling agent possessing short molecules promoted only better fiber adhesion to the coupling agents and stimulated the more intense counterpart heating. The composites were more worn out as a result of frictional heating. Thus, higher wear resistance of the "UHMWPE + $23 \mathrm{wt}$. \% wollastonite" composites loaded with the "less effective" coupling agents was due to the possibility of their more flexible "adjustment" to the severe conditions of tribological loading.

\section{Conclusions}

The tribological and mechanical properties of the wear-resistant UHMWPE-based composites loaded with wollastonite microfibres silanitized with various coupling agents ("KH-550", "Penta-1006", and "OTS") were investigated.

It was shown that the mechanical properties of UHMWPE-based composites filled with various amounts of wollastonite (7-23 wt. \%) increased by 1.8 times (elastic modulus) and 1.3 times (yield strength), while the wollastonite silanization further improved yield strength by $9 \%$ in some cases. It was enhanced up to $25.4 \mathrm{MPa}$ (with the maximum wollastonite content of $23 \mathrm{wt}$. \% treated with the most efficient "KH-550" coupling agent) compared to the lowest level of $23.2 \mathrm{MPa}$.

It was demonstrated that the friction coefficient decreased down to 0.085-0.090 when filling UHMWPE with untreated wollastonite. However, the filler silanization increased the friction coefficient to the level of neat UHMWPE.

It has been found that the composite loaded with $23 \mathrm{wt}$. \% wollastonite silanized with the "KH-550" coupling agent possessed the maximum wear resistance under the "moderate" conditions of tribological loading $\left(\mathrm{P}=60 \mathrm{~N}, \mathrm{~V}=0.3 \mathrm{~m} \cdot \mathrm{s}^{-1}\right)$. Under the "severe" conditions $\left(\mathrm{P}=140 \mathrm{~N}, \mathrm{~V}=0.5 \mathrm{~m} \cdot \mathrm{s}^{-1}\right)$, the composites containing 23 wt. \% wollastonite silanized with the less efficient "OTS" and "Penta-1006" 
agents showed the greatest wear resistance during dry sliding friction. Wear resistance significantly depended on filler weight fraction and the load-speed mode of the tribological tests.

Silanization with the coupling agents made it possible to improve wear resistance of the composites under the "moderate" conditions, when the wear mechanism was predominantly of the fatigue type. Under the "severe" conditions, temperature in the tribological contact increased, causing a decrease in the mechanical properties. In addition, oxidation processes developed and became decisive. In this case, the functionalization with the most active coupling agents reduced wear resistance. On the other hand, the complex shapes of filler microfibers provided a high level of (mechanical) adhesion, as well as the improved mechanical properties and wear resistance.

Based on the obtained experimental data on the mechanical (including impact toughness) and tribological properties of the UHMWPE-based composites loaded with wollastonite, the optimal compositions (the filler content and the type of the coupling agent) for two load-speed modes were designed using the developed computer algorithm. The composites provided the predefined high tribomechanical properties for operation in the metal-polymer friction units.

Author Contributions: S.A.B., and I.L.P. conducted the computer simulation; V.O.A., D.G.B., Q.H., and N.V.R. carried out the experiments; D.G.B., and L.A.K. analyzed and interpreted the data; S.V.P., F.B., L.A.K., and S.A.B. wrote the paper. All authors have read and agreed to the published version of the manuscript.

Funding: This study was carried out by the government research funds in ISPMS SB RAS; project No. III.23.1.3. Authors acknowledge RFBR support via grants 19-38-90106 and 20-58-00032. The research was supported by the RF President Council through the Grant NSh-2718.2020.8.

Acknowledgments: Impact toughness tests were carried out at the National Research Tomsk Polytechnic University, within the framework of the Competitiveness Enhancement Program of Tomsk Polytechnic University. Some experiments were carried out using the large-scale research facilities «Complex of testing and diagnostic equipment for studying properties of structural and functional materials under complex thermomechanical loading PNRPU.

Conflicts of Interest: The authors declare no conflict of interest.

\section{References}

1. Kurtz, S.M. UHMWPE Biomaterials Handbook: Ultra High Molecular Weight Polyethylene in Total Joint Replacement and Medical Devices, 3rd ed.; William Andrew Publishing: Norwich, NY, USA, 2016; p. 840.

2. Galetz, M.C.; Blar, T.; Ruckdaschel, H.; Sandler, K.W.; Alstadt, V. Carbon Nanofibre-Reinforced Ultrahigh Molecular Weiht Polyethylene for Tribological Applications. J. Appl. Polym. Sci. 2007, 104, 4173-4181. [CrossRef]

3. Wang, Y.; Yin, Z.; Li, H.; Gao, G.; Zhang, X. Friction and wear characteristics of ultrahigh molecular weight polyethylene (UHMWPE) composites containing glass fibers and carbon fibers under dry and water-lubricated conditions. Wear 2017, 380-381, 42-51. [CrossRef]

4. Briscoe, B.J.; Sinha, S.K. Tribological applications of polymers and their composites: Past, present and future prospects. Tribol. Interface Eng. Ser. 2008, 55, 1-14.

5. Sperling, L.H. Introduction to Physical Polymer Science, 4th ed.; John Wiley \& Sons: Chichester, NY, USA, 2006; p. 845.

6. Brach del Prever, E.M.; Bistolfi, A.; Bracco, P.; Costa, L. UHMWPE for arthroplasty: Past or future? J. Orthop. Traumatol. 2009, 10, 1-8. [CrossRef] [PubMed]

7. Jacobs, C.A.; Christensen, C.P.; Greenwald, A.S.; McKellop, H. Clinical performance of highly cross-linked polyethylenes in total hip arthroplasty. J. Bone Joint Surg. Am. 2007, 89, 2779-2786. [CrossRef]

8. Galliera, E.; Ragone, V.; Marazzi, M.G.; Selmin, F.; Banci, L.; Massimiliano, M.; Romanelli, C. Vitamin E-stabilized UHMWPE: Biological response on human osteoblasts to wear debris. Clin. Chim. Acta 2018, 486, 18-25. [CrossRef]

9. Chang, T.; Guo, Z.; Yuan, C. Study on influence of Koch snowflake surface texture on tribological performance for marine water-lubricated bearings. Tribol. Int. 2019, 129, 29-37. [CrossRef]

10. Qin, H.; Zhou, X.; Zhao, X.; Xing, J.; Yan, Z. A new rubber/UHMWPE alloy for water-lubricated stern bearings. Wear 2015, 328-329, 257-261. [CrossRef] 
11. Chang, T.; Yuan, C.; Guo, Z. Tribological behavior of aged UHMWPE under water-lubricated condition. Tribol. Int. 2019, 133, 1-11. [CrossRef]

12. Wang, A.; Stark, C.; Dumbleton, J.H. Mechanistic and morphological origins of ultra-high molecular weight polyethylene wear debris in total joint replacement prostheses. Proc. Inst. Mech. Eng. H 1996, 210, 141-155. [CrossRef]

13. McKellop, H.; Clarke, I.; Markolf, K.; Amstutz, H. Friction and wear properties of polymer, metal, and ceramic prosthetic joint materials evaluated on a multichannel screening device. J. Biomed. Mater. Res. 1981, 15, 619-653. [CrossRef] [PubMed]

14. Chandrasekaran, M.; Wei, L.Y.; Venkateshwaran, K.K.; Batchelor, A.W.; Loh, N.L. Tribology of UHMWPE tested against a stainless steel counterface in unidirectional sliding in presence of model synovial fluids: Part 1. Wear 1998, 223, 13-21. [CrossRef]

15. Marcus, K.; Ball, A.; Allen, C. The effect of grinding direction on the nature of the transfer layer formed during the sliding wear of ultrahigh molecular weight polyethylene against stainless steel. Wear 1991, 151, 2323-2336. [CrossRef]

16. Galetz, M.C.; Glatzel, U. Molecular Deformation Mechanisms in UHMWPE During Tribological Loading in Artificial Joints. Tribol. Lett. 2010, 38,1-13. [CrossRef]

17. Saikko, V. Effect of contact area on the wear of ultrahigh molecular weight polyethylene in noncyclic pin-on-disk tests. Tribol. Int. 2017, 114, 84-87. [CrossRef]

18. Oral, E.; Doshi, B.N.; Gul, R.M.; Neils, A.L.; Kayandan, S.; Muratoglu, O.K. Peroxide cross-linked UHMWPE blended with vitamin E. J. Biomed. Mater. Res. Part B 2017, 105, 1379-1389. [CrossRef]

19. Tang, C.Y.; Xie, X.L.; Wu, X.C.; Li, R.K.; Mai, Y.W. Enhanced wear performance of ultrahigh molecular weight polyethylene crosslinked by organosilane. J. Mater. Sci. Mater. Med. 2002, 13, 1065-1069. [CrossRef] [PubMed]

20. Wang, H.; Xu, L.; Zhang, M.; Li, R.; Xing, Z.; Hu, J.; Wang, M.; Wu, G. More wear-resistant and ductile UHMWPE composite prepared by the addition of radiation crosslinked UHMWPE powder. J. Appl. Polym. Sci. 2017, 134, 44643-44654. [CrossRef]

21. Bhateja, S.K.; Duerst, R.W.; Aus, E.B.; Andrews, E.H. Free radicals trapped in polyethylene crystals. J. Macromol. Sci. Part B Phys. 1995, 34, 263-272. [CrossRef]

22. Taromsari, S.M.; Salari, M.; Bagheri, R.; Sani, M.A.F. Optimizing tribological, tensile \& in-vitro biofunctional properties of UHMWPE based nanocomposites with simultaneous incorporation of graphene nanoplatelets (GNP) \& hydroxyapatite (HAp) via a facile approach for biomedical applications. Compos. Part B Eng. 2019, 175, 107-181.

23. Shi, G.; Cao, Z.; Yan, X.; Wang, Q. In-situ fabrication of a UHMWPE nanocomposite reinforced by $\mathrm{SiO}_{2}$ nanospheres and its tribological performance. Mater. Chem. Phys. 2019, 236, 121-778. [CrossRef]

24. Chukov, D.I.; Stepashkin, A.A.; Maksimkin, A.V.; Tcherdyntsev, V.V.; Kaloshkin, S.D.; Kuskov, K.V.; Bugakov, V.I. Investigation of structure, mechanical and tribological properties of short carbon fiber reinforced UHMWPE-matrix composites. Compos. Part B Eng. 2015, 76, 79-88. [CrossRef]

25. Park, S.J.; Jin, J.S. Effect of silane coupling agent on interphase and performance of glass filers/unsaturated polyester composites. J. Colloid Interface Sci. 2001, 242, 174-179. [CrossRef]

26. Saikko, V. Effect of contact area on the wear and friction of UHMWPE in circular translation pin-on-disk tests. J. Tribol. 2017, 139, 061606. [CrossRef]

27. Liu, T.; Li, B.; Lively, B.; Eyler, A.; Zhong, W. Enhanced wear resistance of high-density polyethylene composites reinforced by organosilane-graphitic nanoplatelets. Wear 2014, 309, 43-51. [CrossRef]

28. Qiujun, L.; Feng, H.; Ming, Y.; Di, Y. The addition of acid treated carbon nanotube on the interfacial adhesion of carbon fiber reinforced UHMWPE composite. Surf. Interface Anal. 2017, 49, 717-720. [CrossRef]

29. Han, L.; Cai, H.; Chen, X.; Zheng, C.; Guo, W. Study of UHMWPE Fiber Surface Modification and the Properties of UHMWPE/Epoxy Composite. Polymers 2020, 12, 521. [CrossRef]

30. Herrera-Franco, P.J.; Valadez-González, A. Mechanical properties of continuous natural fibre-reinforced polymer composites. Compos. Part A Appl. Sci. Manuf. 2004, 35, 339-345. [CrossRef]

31. Herrera-Franco, P.J.; Valadez-González, A. A study of the mechanical properties of short natural-fiber reinforced composites. Compos. Part B Eng. 2005, 36, 597-608. [CrossRef]

32. Sepe, R.; Bollino, F.; Boccarusso, L.; Caputo, F. Influence of chemical treatments on mechanical properties of hemp fiber reinforced composites. Compos. Part B Eng. 2018, 133, 210-217. [CrossRef] 
33. Dayyoub, T.; Maksimkin, A.V.; Senatov, F.S.; Kaloshkin, S.D.; Zimina, A.; Kolesnikov, E.A. Treating UHMWPE surface for enhancing the adhesion properties by cellulose grafting. Int. J. Adhes. Adhes. 2019, 98, 102535. [CrossRef]

34. Borisova, R.V.; Spiridonov, A.M.; Okhlopkova, T.A.; Nikiforov, L.A.; Golikov, A.N.; Shadrinov, N.V.; Okhlopkova, A.A. Bromination of UHMWPE surface as a method of changing adhesion to nanoparticles. Mater. Today Commun. 2018, 14, 65-71. [CrossRef]

35. Avinash Patil, N.; Njuguna, J.; Kandasubramanian, B. UHMWPE for Biomedical Applications: Performance and Functionalization. Eur. Polym. J. 2020, 125, 109529. [CrossRef]

36. Tong, J.; Ma, Y.; Jiang, M. Effects of the wollastonite fiber modification on the sliding wear behavior of the UHMWPE composites. Wear 2003, 255, 734-741. [CrossRef]

37. Han, Y.; Chen, J. Experimental investigation on tribological properties of UHMWPE with the addition of basalt fiber. Adv. Compos. Lett. 2019, 28, 1-8. [CrossRef]

38. Bakshi, S.R.; Tercero, J.E.; Agarwal, A. Synthesis and characterization of multiwalled carbon nanotube reinforced ultra-high molecular weight polyethylene composite by electrostatic spraying technique. Compos. Part A 2007, 38, 2493-2499. [CrossRef]

39. Tong, J.; Ma, Y.; Arnell, R.D.; Ren, L. Free abrasive wear behavior of UHMWPE composites filled with wollastonite fibers. Compos. Part A 2006, 37, 38-45. [CrossRef]

40. Yamaguchi, S.; Yabutsuka, T.; Hibino, M.; Yao, T. Development of novel bioactive composites by electrophoretic deposition. Mater. Sci. Eng. C 2009, 29, 1584-1588. [CrossRef]

41. Bulatovic, S.M. Chapter 30-Wollastonite. In Handbook of Flotation Reagents: Chemistry, Theory and Practice Volume 3: Flotation of Industrial Minerals, 1st ed.; Bulatovic, S.M., Ed.; Elsevier: Amsterdam, The Netherlands, 2015; pp. 77-89.

42. Panin, S.V.; Kornienko, L.A.; Huang, Q.; Buslovich, D.G.; Bochkareva, S.A.; Alexenko, V.O.; Panov, I.L.; Berto, F. Effect of Adhesion on Mechanical and Tribological Properties of Glass Fiber Composites, Based on Ultra-High Molecular Weight Polyethylene Powders with Various Initial Particle Sizes. Materials 2020, 13, 1602. [CrossRef]

43. Pasquini, N. Polypropylene Handbook, 2nd ed.; Hanser Publications: Cincinnati, OH, USA, 2005; p. 584.

44. Pape, P.G. Chapter 25-Adhesion Promoters: Silane Coupling Agents. In Plastics Design Library, Applied Plastics Engineering Handbook, 2nd ed.; Kutz, M., Ed.; William Andrew Publishing: Norwich, NY, USA, 2017; pp. 555-572.

45. Panin, S.V.; Kornienko, L.A.; Qitao, H.; Alexenko, V.O.; Ivanova, L.R. Functionalization of powder and fibrous microfillers for UHMWPE by treatment with polyorganosiloxane. In Proceedings of the 11th International Conference on Mechanics, Resource and Diagnostics of Materials and Structures, Ekaterinburg, Russia, 11-15 December 2017; Gorkunov, E.S., Panin, V.E., Ramasubbu, S., Eds.; American Institute of Physics: Melville, NY, USA, 2017; p. 1915.

46. Pajarito, B.B.; Caguntas, A.J.F.; Felices, N.B.; Tubalinal, H.O.S.; Leuterio, G.L.D. Effect of Silane-Treated Mineral Fillers on Corrosion, Wettability, and Adhesion of Saturated Polyester Coated on Carbon Steel. Key Eng. Mater. 2018, 775, 305-310. [CrossRef]

47. Chan, J.X.; Wong, J.F.; Hassan, A.; Mohamad, Z.; Othman, N. Mechanical properties of wollastonite reinforced thermoplastic composites: A review. Polym. Compos. 2019, 41, 395-429. [CrossRef]

48. Panin, S.V.; Kornienko, L.A.; Alexenko, V.O.; Buslovich, D.G.; Bochkareva, S.A.; Lyukshin, B.A. Increasing Wear Resistance of UHMWPE by Loading Enforcing Carbon Fibers: Effect of Irreversible and Elastic Deformation, Friction Heating, and Filler Size. Materials 2020, 13, 338. [CrossRef] [PubMed]

49. Bochkareva, S.A.; Grishaeva, N.Y.; Buslovich, D.G.; Kornienko, L.A.; Lyukshin, B.A.; Panin, S.V.; Panov, I.L.; Dontsov, Y.V. Development of a Wear-Resistant Extrudable Composite Material Based on an Ultrahigh-Molecular Polyethylene with Predetermined Properties. Mech. Compos. Mater. 2020, 56, 15-26. [CrossRef]

50. Sundarkrishnaa, K.L. Friction Material Composites. Materials Perspective, 1st ed.; Springer: Berlin/Heidelberg, Germany, 2012; p. 329.

51. Plueddemann, E.P. Silane Coupling Agents, 2nd ed.; Plenum Press: New York, NY, USA, 1991; p. 253.

52. Seymour, R.B.; Deanin, R.D. History of Polymeric Composites; VNU Science Press BV: Utrecht, The Netherlands, 1987; p. 374. 
53. Jemeskens, L.W. Adhesion Improvement by Silane Coupling Agents in Composites. In Interfacial Phenomena in Composite Materials, 1st ed.; Verposet, I., Jones, F., Eds.; Butteworth-Heinemann: Oxford, UK, 1991; pp. 11-15.

54. Ebnesajjad, S.; Landrock, A.H. Adhesives Technology Handbook, 2nd ed.; William Andrew Publishing: Norwich, NY, USA, 2008; p. 475.

55. Kutz, M. Applied Plastics Engineering Handbook: Processing, Materials, and Applications, 2nd ed.; William Andrew Publishing: Norwich, NY, USA, 2016; p. 784.

56. Plueddemann, E.P. Adhesion through Silane Coupling Agents. J. Adhes. 1970, 2, 184-201. [CrossRef]

(C) 2020 by the authors. Licensee MDPI, Basel, Switzerland. This article is an open access article distributed under the terms and conditions of the Creative Commons Attribution (CC BY) license (http://creativecommons.org/licenses/by/4.0/). 